\title{
Acetotrophic Activity Facilitates Methanogenesis from LCFA at Low Temperatures: Screening from Mesophilic Inocula
}

\author{
Suniti Singh $\left(\mathrm{D},{ }^{1}\right.$ Johanna M. Rinta-Kanto, ${ }^{1}$ Riitta Kettunen, ${ }^{1}$ Piet Lens, ${ }^{1,2}$ Gavin Collins, ${ }^{3}$ \\ Marika Kokko, ${ }^{1}$ and Jukka Rintala ${ }^{1}$
}

${ }^{1}$ Faculty of Engineering and Natural Sciences, Tampere University, Tampere, Finland

${ }^{2}$ IHE, Institute for Water Education, Westvest 7, 2611AX Delft, Netherlands

${ }^{3}$ National University of Ireland Galway, University Road, Galway H91 TK33, Ireland

Correspondence should be addressed to Suniti Singh; suniti.singh@tut.fi

Received 14 October 2018; Revised 14 February 2019; Accepted 3 April 2019; Published 2 May 2019

Academic Editor: Alla Nozhevnikova

Copyright ( 2019 Suniti Singh et al. This is an open access article distributed under the Creative Commons Attribution License, which permits unrestricted use, distribution, and reproduction in any medium, provided the original work is properly cited.

\begin{abstract}
The inoculum source plays a crucial role in the anaerobic treatment of wastewaters. Lipids are present in various wastewaters and have a high methanogenic potential, but their hydrolysis results in the production of long chain fatty acids (LCFAs) that are inhibitory to anaerobic microorganisms. Screening of inoculum for the anaerobic treatment of LCFA-containing wastewaters has been performed at mesophilic and thermophilic conditions. However, an evaluation of inocula for producing methane from LCFA-containing wastewater has not yet been conducted at low temperatures and needs to be undertaken. In this study, three inocula (one granular sludge and two municipal digester sludges) were assessed for methane production from LCFA-containing synthetic dairy wastewater $(\mathrm{SDW})$ at low temperatures $\left(10\right.$ and $\left.20^{\circ} \mathrm{C}\right)$. A methane yield (based on $\left.\mathrm{mL}^{-} \mathrm{CH}_{4} / \mathrm{g}-\mathrm{COD}_{\text {added }}\right)$ of 86-65\% with acetate and 45-20\% with SDW was achieved within 10 days using unacclimated granular sludge, whereas the municipal digester sludges produced methane only at $20^{\circ} \mathrm{C}$ but not at $10^{\circ} \mathrm{C}$ even after 200 days of incubation. The acetotrophic activity in the inoculum was found to be crucial for methane production from LCFA at low temperatures, highlighting the role of Methanosaeta (acetoclastic archaea) at low temperatures. The presence of bacterial taxa from the family Syntrophaceae (Syntrophus and uncultured taxa) in the inoculum was found to be important for methane production from SDW at $10^{\circ} \mathrm{C}$. This study suggests the evaluation of acetotrophic activity and the initial microbial community characteristics by highthroughput amplicon sequencing for selecting the inoculum for producing methane at low temperatures (up to $10^{\circ} \mathrm{C}$ ) from lipid-containing wastewaters.
\end{abstract}

\section{Introduction}

High rate anaerobic treatment is an efficient solution to treat wastewaters without expending energy for aeration and to simultaneously produce a bioenergy source as methane. Mesophilic conditions have been commonly applied for the anaerobic treatment of wastewaters due to the optimal growth temperature range of the microbial consortia [1]. However, numerous wastewaters, including domestic and industrial, are discharged at temperatures of $20^{\circ} \mathrm{C}$ or lower, and their anaerobic treatment at these low temperatures could improve the net energy gain from the treatment process.
Over 700 billion metric tons of milk is produced annually worldwide, which leads to the generation of huge volumes of dairy wastewaters $[2,3]$. These dairy effluents constitute high amounts of lipids (35-500 mg/L) along with carbohydrates and proteins [4], and the presence of each of these constituents poses specific challenges. Lipids have a higher methanogenic potential than carbohydrates or proteins [5], but their anaerobic treatment is challenging due to the synergistic inhibitory effects of their hydrolysis by-products [6-10]. Single compounds $[11,12]$ as well as industrial wastewaters [13-16] have been treated anaerobically at low temperatures. Yet, the anaerobic treatment of lipids at low temperatures $\left(\leq 20^{\circ} \mathrm{C}\right)$ remains understudied. 
During lipolysis, the lipids hydrolyze to long chain fatty acids (LCFAs) which are inhibitory to acidogens, acetogens, and methanogens, even at low concentrations $[6-9,17]$. For example, at $21^{\circ} \mathrm{C}, 30 \mathrm{mg} / \mathrm{L}$ of linoleic acid, $30 \mathrm{mg} / \mathrm{L}$ of oleic acid, and $10 \mathrm{mg} / \mathrm{L}$ of stearic acid inhibit methane production from $100 \mathrm{mg} / \mathrm{L}$ of acetate $[18,19]$. Additionally, LCFA impedes methane production by imposing mass-transfer limitations and preventing aggregation of acetogens and methanogens $[20,21]$. Although the individual and synergistic inhibitory effects of LCFA (oleic, stearic, and linoleic acids) on hydrogen, glucose, and butyrate fermentation have been studied in batch at $21^{\circ} \mathrm{C}$, the methane production was not reported [7] which obscures the potential use of LCFA as a methanogenic precursor under psychrophilic conditions. Investigations on the anaerobic treatment of dairy wastewaters $(4 \mathrm{~g}$-COD/L) with a low fat content of $40 \mathrm{mg}-\mathrm{COD} / \mathrm{L}$ (typically $<1 \%$ of the total chemical oxygen demand) have been conducted previously at temperatures as low as 10 and $15^{\circ} \mathrm{C}$ [22]. Very recently, the knowledge on lipid treatment has been extended to low temperatures for the assessment of lipase activity at reduced temperatures $\left(4,8\right.$, and $\left.15^{\circ} \mathrm{C}\right)$ in domestic wastewater [23]. Yet, methane production from LCFA mixtures has not been reported at a lipid content $>1 \%$ at low temperatures and warrants further investigation.

The inoculum source plays a crucial role in anaerobic treatment and more so at low temperatures, as the microbial community in the inoculum affects the substrate-degradation potential and the methanogenic activity [24, 25]. Both suspended and granular sludges have been used in low temperature anaerobic digestion (LTAD) studies to treat various wastewaters [13, 15, 22, 26-31]. Previous comparisons of granular to suspended sludges at low temperatures for methane production have contrasting conclusions, and their suitability appears to be case-specific. At $15^{\circ} \mathrm{C}$, when Xing et al. [32] compared inocula from permafrost sites (lake sediment, pond silt, and wetlands) to mesophilic granular sludge, a higher methane production rate $\left(71 \mathrm{~mL}-\mathrm{CH}_{4} / \mathrm{gVSS} \cdot \mathrm{d}\right)$ from glucose of around 2 times was achieved using the waterfowl lake sediment (suspended sludge) compared to the other inocula. Conversely, at $15^{\circ} \mathrm{C}$ when Enright et al. [30] compared a sludge mixture (waste-activated sludge, cattle manure, and non-granular anaerobic sludge) to two granular sludges, more methane was produced by the granular sludges from acetate, $\mathrm{H}_{2} / \mathrm{CO}_{2}$, and ethanol.

In the anaerobic treatment of lipid-containing wastewater, both suspended sludge and granular sludge have been used as inoculum at mesophilic and thermophilic conditions. Granular sludge has been reported to be suitable for anaerobic LCFA treatment due to its lower specific surface area [33], a higher methanogenic activity (acetoclastic, hydrogenotrophic, propionate, and ethanol fermentation), and a lower oleate toxicity compared to suspended sludge while treating oleate (OLR 2-8 g-COD/L.d) $[34,35]$. However, usage of suspended sludge as an inoculum source has been suggested for treating oleate-containing wastewater due to its higher LCFA sorption capacity [34, 35], as LCFA sorption is required for its degradation based on a sequential sorption-desorption mechanism [36]. Therefore, an evaluation of different inocula is needed for assessing the methane production from LCFA-containing wastewaters at low temperatures.

Apart from the physicochemical characteristics, the microbial community composition of the anaerobic sludge is affected by the high lipid or LCFA concentration and by the low temperature. LCFA degradation proceeds through the removal of 2 carbons in each $\beta$-oxidation cycle usually resulting in the production of acetate. In a microbial consortium, this $\beta$-oxidation requires the syntrophic coupling of acetogenic bacteria to the hydrogenotrophic methanogens to maintain low hydrogen partial pressures. The microbial communities involved in codigesting fat, oil, and grease (FOG) or LCFA at mesophilic and thermophilic conditions have been deciphered using high-throughput amplicon sequencing, and syntrophs have been concluded to also play a significant role in their degradation [37-40]. Only 7 acetogenic bacteria belonging to the families Syntrophomonadaceae (class Clostridia) and Syntrophaceae (class Deltaproteobacteria) $[5,41]$ are currently known to degrade LCFA, and the bacteria from the family Clostridiaceae (class Clostridia) have been suggested to degrade LCFA [42, 43], signifying the importance of bacterial taxa from these 3 families in LCFA degradation. Furthermore, the predominance of hydrogenotrophic methanogens has not been established at low temperatures in the anaerobic treatment of wastewaters with low-lipid and LCFA content $[1,16,44-48]$ due to the thermodynamic preference for hydrogen utilization than acetate utilization at low temperatures [49]. An investigation of the microbial consortia involved in degrading the lipid- or LCFA-containing wastewaters at low temperatures through high-throughput amplicon sequencing has not yet been applied to the microbial consortia involved in degrading the lipid- or LCFA-containing wastewaters at low temperatures and could provide novel insights about the key taxa involved.

As the choice of inoculum for LTAD depends on its unique physicochemical characteristics and microbial community composition, the objective of this study was to assess the effect of the inoculum source on methane production from LCFA-containing synthetic dairy wastewater (SDW) in batch assays at low temperatures of 20 and $10^{\circ} \mathrm{C}$. Amplicon sequencing was applied to characterize the microbial communities before and after the batch operation to study the changes in microbial community composition during incubation.

\section{Materials and Methods}

2.1. Inoculum and Substrate. Three inocula obtained from local sources were used in this study - two suspended sludges and one granular sludge. Suspended sludges from mesophilic anaerobic digesters of municipal wastewater treatment plants, Rahola (RD) and Viinikanlahti (VD), Tampere, Finland, were collected, sieved with a $16 \mathrm{~mm}$ mesh, and stored for 4 weeks under nitrogen-purged atmosphere at $7^{\circ} \mathrm{C}$. Granular sludge (GS) was obtained from a mesophilic upflow anaerobic sludge blanket (UASB) reactor treating wastewaters from an integrated production of beta-amylase enzyme and ethanol from oat (Jokioinen, Finland) and stored 
for 3 weeks in nitrogen-purged atmosphere at $7^{\circ} \mathrm{C}$. The sieved suspended and granular sludges were characterized (Table 1).

SDW and acetate were used as substrates in this study. SDW simulated constituents of dairy wastewater and contained a protein source (casein hydrolysate), a carbohydrate source (lactose monohydrate), and a fat source (LCFA mixture) (Table 2). The LCFA mixture consisted of palmitate, stearate, oleate, and linoleate in a COD ratio of $30: 15: 45: 10$ (Table 2) based on LCFA concentrations frequently found in dairy wastewaters $[41,50]$.

2.2. Methane Production in Batch Assays. Batch studies were performed using $120 \mathrm{~mL}$ serum bottles, with a liquid volume of $60 \mathrm{~mL}$. In all assays, $15 \mathrm{~mL}$ of substrate stock solution (SDW or acetate) and $10-30 \mathrm{~mL}$ of inoculum (GS, RD, or VD) were added into the bottle, to ensure 2 $\mathrm{g}$-COD/L of the substrate and 6 g-volatile solids (VS)/L of inoculum. $2 \mathrm{~mL}$ of stock nutrient solution was added to the bottles consisting of the following $(\mathrm{g} / \mathrm{L}): \mathrm{MgSO}_{4} \cdot 7 \mathrm{H}_{2} \mathrm{O}$ (6), $\mathrm{NH}_{4} \mathrm{Cl}$ (16.8), $\mathrm{KH}_{2} \mathrm{PO}_{4} \cdot 3 \mathrm{H}_{2} \mathrm{O}(0.24), \mathrm{Na}_{2} \mathrm{HPO}_{4} \cdot 2 \mathrm{H}_{2} \mathrm{O}$ (0.2), $\mathrm{CaCl}_{2} \cdot 2 \mathrm{H}_{2} \mathrm{O}$ (6), yeast extract (6), $\mathrm{FeCl}_{2} \cdot 4 \mathrm{H}_{2} \mathrm{O}(0.12)$, $\mathrm{H}_{3} \mathrm{BO}_{3}$ (0.003), $\mathrm{ZnCl}_{2}$ (0.003), $\mathrm{CuCl}_{2} \cdot 2 \mathrm{H}_{2} \mathrm{O}$ (0.002), $\mathrm{MnCl}_{2} \cdot 4 \mathrm{H}_{2} \mathrm{O}(0.03), \mathrm{Na}_{2} \mathrm{MoO}_{4} \cdot 2 \mathrm{H}_{2} \mathrm{O}(0.001), \mathrm{CoCl}_{2} \cdot 6 \mathrm{H}_{2} \mathrm{O}$ (0.12), $\mathrm{NiCl}_{2} \cdot 6 \mathrm{H}_{2} \mathrm{O}(0.005), \mathrm{Na}_{2} \mathrm{SeO}_{3} \cdot 5 \mathrm{H}_{2} \mathrm{O}(0.01)$, EDTA (0.06), and resazurin that was acidified with $1 \mathrm{~mL}$ of $36 \%$ hydrochloric acid prior to usage [51], and the volume was adjusted to $60 \mathrm{~mL}$ with distilled water. Subsequently, the $\mathrm{pH}$ in the assays was adjusted to 7.0 by adding $0.1 \mathrm{M}$ sodium hydroxide or $0.1 \mathrm{M}$ hydrochloric acid solutions. The headspace was flushed with nitrogen gas for $10 \mathrm{~min}$ and closed with a butyl rubber stopper to ensure anaerobic conditions after which it was sealed with aluminum crimp caps. The experiments were performed in triplicates and incubated at 20 or $10^{\circ} \mathrm{C}$ without shaking. Assays without substrates were prepared similarly, to act as blanks. Supernatant and sludge from the bottles were sampled at the end of the trial $(200 \mathrm{~d})$ for soluble COD (sCOD) and volatile fatty acid (VFA) measurements and for microbial community analysis, respectively. Assays prepared with the granular sludge as inocula will be referred to as GS, and the assays prepared with the municipal digester sludges-RD and VD-will be referred to as $\mathrm{RD}$ and $\mathrm{VD}$, respectively, in the subsequent sections. A long assay duration ( $200 \mathrm{~d}$ ) was undertaken due to the possibility for diauxic behavior as seen previously in the anaerobic treatment of LCFA-containing wastewater at $20^{\circ} \mathrm{C}$ in our study (data not published) and of fat-containing dairy effluent at $37^{\circ} \mathrm{C}[52]$.

2.3. Analytical Methods and Calculations. The biogas content $\left(\mathrm{CH}_{4}, \mathrm{CO}_{2}\right.$, and $\left.\mathrm{H}_{2}\right)$ was analyzed using a Shimadzu GC2010 gas chromatograph, equipped with a Porapak N column and a thermal conductivity detector. Helium was used as the mobile phase at a flow rate of $20 \mathrm{~mL} / \mathrm{min}$. Injector, oven, and detector temperatures were set at 110,80 , and $110^{\circ} \mathrm{C}$, respectively. The volume of the gas was measured according to [53] and reported at standard temperature and pressure (STP). Liquid supernatant from the bottles at the end of $200 \mathrm{~d}$ was filtered through $0.45 \mu \mathrm{m}$ polyethersulphone
TABLE 1: Characteristics of the three inocula used in the assays at 10 and $20^{\circ} \mathrm{C}$.

\begin{tabular}{lccc}
\hline Parameters & $\begin{array}{c}\text { Granular } \\
\text { sludge (GS) }\end{array}$ & $\begin{array}{c}\text { Rahola } \\
\text { Digestate (RD) }\end{array}$ & $\begin{array}{c}\text { Viinikanlahti } \\
\text { digestate (VD) }\end{array}$ \\
\hline $\begin{array}{l}\text { Soluble COD } \\
(\mathrm{mg} / \mathrm{L})\end{array}$ & $525 \pm 10$ & $2520 \pm 95$ & $1080 \pm 40$ \\
$\begin{array}{l}\text { Volatile fatty } \\
\text { acids }(\mathrm{mg} / \mathrm{L})\end{array}$ & $147 \pm 2.0$ & $-{ }^{*}$ & $-^{*}$ \\
$\mathrm{pH}$ & $6.8 \pm 0.2$ & $7.3 \pm 0.1$ & $6.9 \pm 0.1$ \\
Alkalinity (mM) & $44.0 \pm 0.1$ & $78.0 \pm 0.1$ & $94.0 \pm 0.1$ \\
$\mathrm{TS}(\mathrm{g} / \mathrm{L})$ & $42.0 \pm 5.0$ & $51.0 \pm 1.5$ & $20.1 \pm 1.0$ \\
$\mathrm{VS}(\mathrm{g} / \mathrm{L})$ & $36.0 \pm 4.0$ & $28.0 \pm 1.0$ & $11.1 \pm 0.2$ \\
$\mathrm{TSS}(\mathrm{g} / \mathrm{L})$ & $39.0 \pm 2.0$ & $51.0 \pm 2.0$ & $20.0 \pm 0.2$ \\
$\left.\mathrm{VSS}^{*} \mathrm{~g} / \mathrm{L}\right)$ & $34.0 \pm 1.6$ & $27.0 \pm 0.15$ & $11.0 \pm 0.2$ \\
$\mathrm{SO}_{4}{ }^{2-}(\mathrm{mg} / \mathrm{L})$ & $4.4 \pm 0.01$ & $184.0 \pm 0.8$ & $67.0 \pm 0.1$ \\
$\mathrm{PO}_{4}{ }^{3-}(\mathrm{mg} / \mathrm{L})$ & $6.6 \pm 0.01$ & $57.0 \pm 0.3$ & $1.5 \pm 0.03$ \\
$\mathrm{Cl}^{-}(\mathrm{mg} / \mathrm{L})$ & $17.0 \pm 0.1$ & $9.0 \pm 0.01$ & $29.0 \pm 0.05$ \\
\hline
\end{tabular}

${ }^{*}$ Below detection limits.

TABLE 2: Composition of the synthetic dairy wastewater (SDW) used as a substrate in the assays with VD, RD, and GS at 10 and $20^{\circ} \mathrm{C}$.

\begin{tabular}{lccc}
\hline $\begin{array}{l}\text { Substrate } \\
\text { component }\end{array}$ & LCFA & \% of COD & $\begin{array}{c}\text { Concentration } \\
(\mathrm{mg} / \mathrm{L})\end{array}$ \\
\hline Casein & & 25 & 348 \\
Lactose & 42 & 730 \\
LCFA, total & 33 & 229 \\
& Palmitate & 10 & 69 \\
& Stearate & 4.9 & 34 \\
& Oleate & 13.2 & 91 \\
& Linoleate & 4.9 & 35 \\
\hline
\end{tabular}

syringe filters for sCOD and VFA measurements. For VFA measurement, a Shimadzu GC-2010 having ZB-Wax column was used for analysis, with helium as carrier gas at a flow rate of $19.6 \mathrm{~mL} / \mathrm{min}$. Injector and FID detector temperatures were both $250^{\circ} \mathrm{C}$. The oven temperature was programmed to heat as follows: at $40^{\circ} \mathrm{C}$ for $2 \mathrm{~min}$, then heated up to $160^{\circ} \mathrm{C}$ with $20^{\circ} \mathrm{C} / \mathrm{min}$ and up to $220^{\circ} \mathrm{C}$ with $40^{\circ} \mathrm{C} / \mathrm{min}$, after which temperature was held at $220^{\circ} \mathrm{C}$ for $2 \mathrm{~min}$.

The sCOD was measured using the potassium dichromate titrimetric method according to the Finnish standard SFS 5504. Total solids (TS), VS, total suspended solids (TSS), and volatile suspended solids (VSS) were measured according to APHA 2005 and alkalinity according to the Finnish standard SFS 3005. The concentrations of anions $\left(\mathrm{SO}_{4}{ }^{2-}, \mathrm{PO}_{4}{ }^{3-}\right.$, and $\left.\mathrm{Cl}^{-}\right)$in filtered samples were measured by a Dionex ICS-1600 Ion Chromatography System, equipped with an IonPac AS4A-SC anion exchange column, a DS6 heated conductivity cell, and $1.9 \mathrm{mM} \mathrm{Na}_{2} \mathrm{CO}_{3}$ and $1.7 \mathrm{mM} \mathrm{NaHCO}$ as the eluent at a flow rate of $1 \mathrm{~mL} / \mathrm{min}$.

Salinity measurements of the substrates were used for calculating dissolved gas (methane and carbon dioxide) 
concentrations and were carried out using a handheld conductivity meter WTW Cond 3210. Bunsen solubility coefficients were obtained using constant values from Yamamoto et al. [54] and were applied to estimate solubilized methane [55].

Methane production was determined by adding the methane dissolved in the liquid phase to the methane volume in the gaseous phase and subtracting the methane production in the assay blanks from this value. The methane yield (\%) was calculated from the ratio of methane produced in each assay (mL/g-COD) to the theoretical methane volume produced per gram COD at standard temperature and pressure (STP) $(350 \mathrm{~mL} / \mathrm{g}$-COD). Overall mass balances were performed in terms of COD at the beginning (Table 2) and at the end of the $200 \mathrm{~d}$ experiment for all the assays.

The cumulative methane production from the assays was fitted with the modified Gompertz equation:

$$
M(t)=P \cdot \exp \left[-\exp \left\{\frac{R_{\mathrm{m}} \cdot e}{P}(\lambda-t)+1\right\}\right]
$$

where $M(t)$ is the cumulative methane production (mL$\mathrm{CH}_{4}$ ) at time $t(\mathrm{~d}), P$ is the methane production potential (mL- $\mathrm{CH}_{4}$ or $\mathrm{mL}-\mathrm{CH}_{4} / \mathrm{gVS}$ ), $R_{\mathrm{m}}$ is the maximum methane production rate $\left(\mathrm{mL}-\mathrm{CH}_{4} / \mathrm{d}\right)$, and $\lambda$ is the lag phase for methane production (d). The curve fitting tool in MATLAB R2017b was used to calculate the lag phase $(\lambda)$ and the maximum methane production rate $\left(R_{\mathrm{m}}\right)$.

2.4. DNA Extraction, Quantification, and 16S rRNA Amplicon Sequencing. The microbial samples (three inocula and from all the assays after 200-day incubations) were stored at $-20^{\circ} \mathrm{C}$ immediately upon sampling. After thawing the samples at $4^{\circ} \mathrm{C}$, the total DNA was coextracted along with RNA from the microbial samples [56]. The concentration of extracted DNA was quantified with a Qubit Fluorometer (Life Technologies), and the DNA purity was measured using a NanoDrop spectrophotometer (NanoDrop Technologies, Wilmington, USA). The DNA samples were sent to FISABIO (Spain) for PCR amplification of the V4 region of the 16S rRNA gene with universal primers 515f and 806r [57] and amplicon sequencing with the Illumina MiSeq platform.

2.5. Bioinformatics and Statistical Tools. Computational analysis of the sequenced data was done using the Quantitative Insights Into Microbial Ecology (QIIME v1.9) pipeline [58]. The average length of the forward and reverse reads was 291 and $294 \mathrm{bp}$, respectively. The paired-end reads were joined using a fastq-join method [59] with a min overlap of 50 bp and a perc_max_diff of 15\%, after which quality filtering was performed using the split_libraries_fastq.py script in QIIME [58]. The sequences were clustered into operational taxonomic units (OTUs) using the open-reference OTU picking with the BLAST method, and taxonomy assignment was performed with the Silva 128 consensus taxonomy at all levels $[60,61]$. Chimeric sequences were identified using ChimeraSlayer, and the final OTU table was generated from the nonchimeric sequences using the script make_otu_ table.py.

The dataset consisted of 5743805 sequences in total, which clustered into 12326 OTUs at 97\% similarity level. There were 127 abundant OTUs that formed $99.9 \%$ of the community which were subsampled to an even sequencing depth of 26511 (based on the number of reads in the smallest sample) for alpha diversity metrics (diversity within samples). Community diversity and species richness were estimated using Chaol and Shannon indices and the number of observed OTUs. The alpha diversity indices for the inoculum duplicates and assay triplicates are presented as the averaged values of the microbial community composition within the inoculum duplicates or within the experimental assay triplicates after 200 days.

The subsampled data set consisting of sequences representing the 127 most abundant OTUs was used in subsequent analyses. The subsampled OTU table was fourth-roottransformed for even distribution, and a resemblance matrix was constructed using Bray-Curtis similarity in the Plymouth Routines In Multivariate Ecological Research (PRIMER) V7 [62]. Cluster analysis was performed to discern patterns in the microbial community of the different inocula in the low temperature treatment of LCFA-containing wastewater. Cluster analysis through hierarchical clustering (group average method) was performed at the taxonomic class level on the operational taxonomic units (OTUs) and separately on the assay samples to plot the dendrograms. The fourth-root-transformed OTU table was used for representing the microbial community composition in a shade plot with dendrograms.

\section{Results and Discussion}

\subsection{Inoculum Characteristics and Microbial Community Composition}

3.1.1. Physicochemical Characteristics. Among the three mesophilic inocula, the granular sludge (GS) had a higher VS : TS ratio (0.86) compared to the municipal digester sludges-RD and VD (0.55) - while GS had lower sCOD than the municipal digester sludges (520 vs. $1100-2500 \mathrm{mg} / \mathrm{L}$ ) (Table 1). GS contained some VFA (147 mg/L) whereas the VFA was lower than the detection limit in both of the municipal digester sludges. The two municipal digester sludges differed in several properties; e.g., the TS, sCOD, and $\mathrm{PO}_{4}{ }^{3-}$ concentrations were several-fold different (Table 1) suggesting the impact of inflow wastewater characteristics and plant operation, as the two municipal wastewater treatment facilities have similar unit processes, which are the primary sedimentation and activated sludge processes, followed by mesophilic anaerobic digestion of the excess sludge generated.

\subsubsection{Microbial Community Composition of the Inocula.} High-throughput amplicon sequencing was used to investigate the microbial community composition of the three inocula. The municipal digester sludges (RD and VD) had a higher microbial community diversity (Chaol: 104-108, 
Shannon: 4.53-4.73, observed_otus: 103-105) compared to the GS inoculum (Chao1: 93, Shannon: 3.69, observed_otus: 79) (Table 3), although the three inocula were obtained from mesophilic reactors. The bacterial classes Anaerolineae (relative abundance 7.4-23.25\%), Clostridia (relative abundance 0.1-0.6\%), and Synergistia (relative abundance 6.3-10.6\%) and the archaeal class Methanomicrobia (relative abundance $7.8-19 \%)$ were present in all the three inocula. Although the municipal digester sludges (RD and VD) had a similar microbial community composition, the relative abundance of Methanomicrobia (13 vs. 7\%) and Anaerolineae (23 vs. $13 \%)$ was higher in RD than in VD inoculum. Overall, GS inoculum had a high relative abundance of Methanobacteria (21.5\%), uncultured Aminicenantes (25\%), and Deltaproteobacteria (5\%) compared to that of the municipal digester sludges.

The microbial community composition and diversity in the three inocula were different. The higher microbial community diversity in the municipal digester sludges (Table 3) was likely due to the wide variety of substrates received by the municipal wastewater treatment plants. In comparison, GS was sourced from an UASB treating carbohydrate and alcohol-based wastewater, which potentially narrowed the diversity of the microbial community.

To date, only 7 species from the classes Clostridia or Deltaproteobacteria are known to degrade LCFA (carbon atoms $>12$ ) of which only 4 species (Syntrophomonas sapovorans, Syntrophomonas curvata, Syntrophomonas zehnderi, and Thermosyntropha lipolytica) from the class Clostridia are currently known to degrade the unsaturated LCFAs, e.g., oleate and linoleate [5], and have also been found in various LCFA-fed digesters [63-66]. Moreover, at low temperatures, the Deltaproteobacterial class plays a significant role along with the archaeal classes of Methanobacteria and Methanomicrobia [22, 44, 45, 47, 67, 68]. Therefore, monitoring the bacterial and the archaeal taxa belonging to the classes Deltaproteobacteria and Clostridia, and Methanobacteria and Methanomicrobia, respectively, was considered of special interest while investigating anaerobic LCFA treatment at low temperatures in this study.

3.2. Methane Production at Low Temperature from SDW and Acetate. The potential of the three different inocula for methane production from SDW and acetate was studied in batch assays at 10 and $20^{\circ} \mathrm{C}$ (Figure 1). Blank assays without any added substrates were prepared to subtract the methane production from their corresponding assays with the added substrates. The cumulative methane production curves were fitted with the Gompertz equation ( $R$-square: $0.9-0.99)$ and were used for calculating the lag time and the maximum methane production rate $\left(R_{\mathrm{m}}\right)$.

Granular sludge (GS) inoculum started methane production rapidly both at $20^{\circ} \mathrm{C}(0.6 \mathrm{~d})$ and $10^{\circ} \mathrm{C}(1.5$ days $)$ with both of the substrates while the other two inocula (VD, $\mathrm{RD})$ had a longer and comparable (20-23 d) lag phase $(\lambda)$ at $10^{\circ} \mathrm{C}$ with acetate and SDW. However, at $20^{\circ} \mathrm{C}$, VD had several-fold longer lag phases than $\mathrm{RD}(18-50 \mathrm{~d}$ vs. $4-9 \mathrm{~d}$, respectively) (Figure 1 , Table 4 ). At $20^{\circ} \mathrm{C}$, the $R_{\mathrm{m}}$ was comparable or higher with GS than the municipal digester sludges
TABLE 3: Alpha diversity metrics (diversity within samples) - Chao 1 indices, Shannon indices, and number of observed OTUs for all the OTUs achieving 99.9\% cut-off in the overall relative abundance. Detailed information on the sample names is shown in Table S1.

\begin{tabular}{lccc}
\hline & Chao1 & Shannon & observed_otus \\
\hline VD inoculum & $108(1)$ & $4.73(0.05)$ & $105(0.5)$ \\
$\mathrm{VD}_{\text {Blank }} 10$ & $106(4)$ & $4.38(0.1)$ & $104(1.2)$ \\
$\mathrm{VD}_{\text {Acetate }} 10$ & $108(3)$ & $4.62(0.07)$ & $106(1.4)$ \\
$\mathrm{VD}_{\text {SDW }} 10$ & $109(3)$ & $4.31(0.04)$ & $105(1.2)$ \\
$\mathrm{VD}_{\text {Blank }} 20$ & $116(12)$ & $5.13(0.01)$ & $109(2.1)$ \\
$\mathrm{VD}_{\text {Acetate }} 20$ & $115(8)$ & $5.06(0.05)$ & $109(1.7)$ \\
$\mathrm{VD}_{\text {SDW }} 20$ & $115(4)$ & $4.79(0.33)$ & $109(0.8)$ \\
$\mathrm{RD} \mathrm{inoculum}^{20}$ & $104(0)$ & $4.53(0.14)$ & $103(0.5)$ \\
$\mathrm{RD}_{\text {Blank }} 10$ & $108(3)$ & $4.76(0.1)$ & $105(2.9)$ \\
$\mathrm{RD}_{\text {Acetate }} 10$ & $113(0)$ & $4.49(0.02)$ & $107(0.5)$ \\
$\mathrm{RD}_{\text {SDW }} 10$ & $114(9)$ & $4.61(0.09)$ & $104(2.4)$ \\
$\mathrm{RD}_{\text {Blank }} 20$ & $112(1)$ & $4.46(0.02)$ & $110(0.1)$ \\
$\mathrm{RD}_{\text {Acetate }} 20$ & $113(1)$ & $5.12(0.04)$ & $111(0.9)$ \\
$\mathrm{RD}_{\text {SDW }} 20$ & $111(4)$ & $4.8(0.2)$ & $109(5)$ \\
$\mathrm{GS}$ inoculum $^{20}$ & $93(14)$ & $3.69(0.01)$ & $79(2.5)$ \\
$\mathrm{GS}_{\text {Blank }} 10$ & $82(16)$ & $3.8(0.13)$ & $70(3.7)$ \\
$\mathrm{GS}_{\text {Acetate }} 10$ & $77(3)$ & $3.86(0.02)$ & $66(2.2)$ \\
$\mathrm{GS}_{\text {SDW }} 10$ & $80(11)$ & $3.78(0.04)$ & $66(1.7)$ \\
$\mathrm{GS}_{\text {Blank }} 20$ & $88(4)$ & $4.02(0.12)$ & $78(2.9)$ \\
$\mathrm{GS}_{\text {Acetate }} 20$ & $87(7)$ & $3.93(0.06)$ & $85(6)$ \\
$\mathrm{GS}_{\text {SDW }} 20$ & $77(3)$ & $4.04(0.18)$ & $76(3.3)$ \\
\hline
\end{tabular}

with SDW (1.6 and 0.9) and acetate (9.5 and 1). At $10^{\circ} \mathrm{C}$ with SDW, the GS had 4.7 times higher $R_{\mathrm{m}}$ than the $\mathrm{RD}$, while other $\mathrm{RD}$ and $\mathrm{VD}$ assays at $10^{\circ} \mathrm{C}$ produced little methane (Table 4). Methane yields within 10 days were substantially higher with the granular sludge- -86 and $65 \%$ with acetate and 45 and $20 \%$ with SDW at 20 and $10^{\circ} \mathrm{C}$, respectively (Figure 1), compared to the municipal digester sludges (methane yields less than 20\%). After 200 days, methane yield with granular sludge was overall comparable at 20 and $10^{\circ} \mathrm{C}$ from acetate $(83-95 \%$ and $91-95 \%$, respectively) or SDW (70-82\% and 79-85\%, respectively) (Table 4). Contrastingly, methane yields from acetate and SDW with the municipal digester sludges (RD and VD) were much higher at $20^{\circ} \mathrm{C}$ $\left(75-93 \%\right.$ and $60-75 \%$, respectively) compared to $10^{\circ} \mathrm{C}$ $(<20 \%)$. The results show that the municipal digester sludges were strongly affected by temperature. Methane was produced with $\mathrm{RD}$ at $10^{\circ} \mathrm{C}$ with SDW but not with acetate which is a simpler methane precursor than SDW.

SCOD removal at $20^{\circ} \mathrm{C}$ was similar with all three inocula, $78-81 \%$ with SDW and $81-90 \%$ with acetate (Fig. S1), but at $10^{\circ} \mathrm{C}$, a higher sCOD removal was obtained with GS $(82 \%$ in SDW-addition and 91\% in acetate-addition) than with the municipal digester sludges. Despite the SCOD removal of $29-53 \%$ in the municipal digester sludges at $10^{\circ} \mathrm{C}$ (Fig. S1), methane production was low (methane yield $<20$ $\%$ ), which suggests that the sCOD removal was apparently due to the sorption by inoculum biomass [36]. Moreover, after 200 days, VFAs were detected only with the municipal 


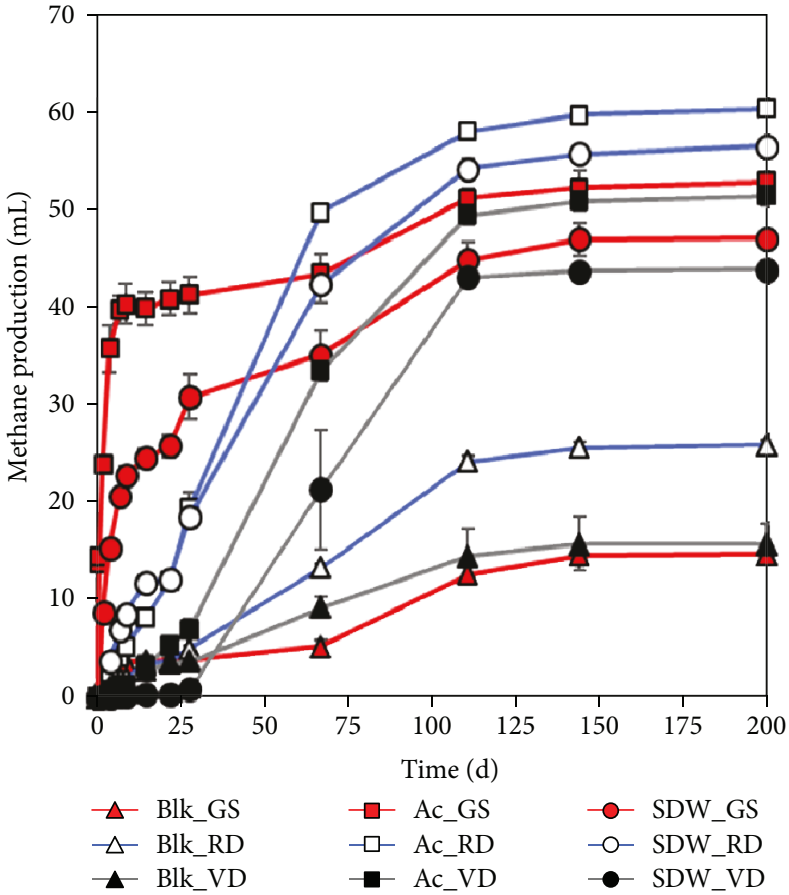

(a)

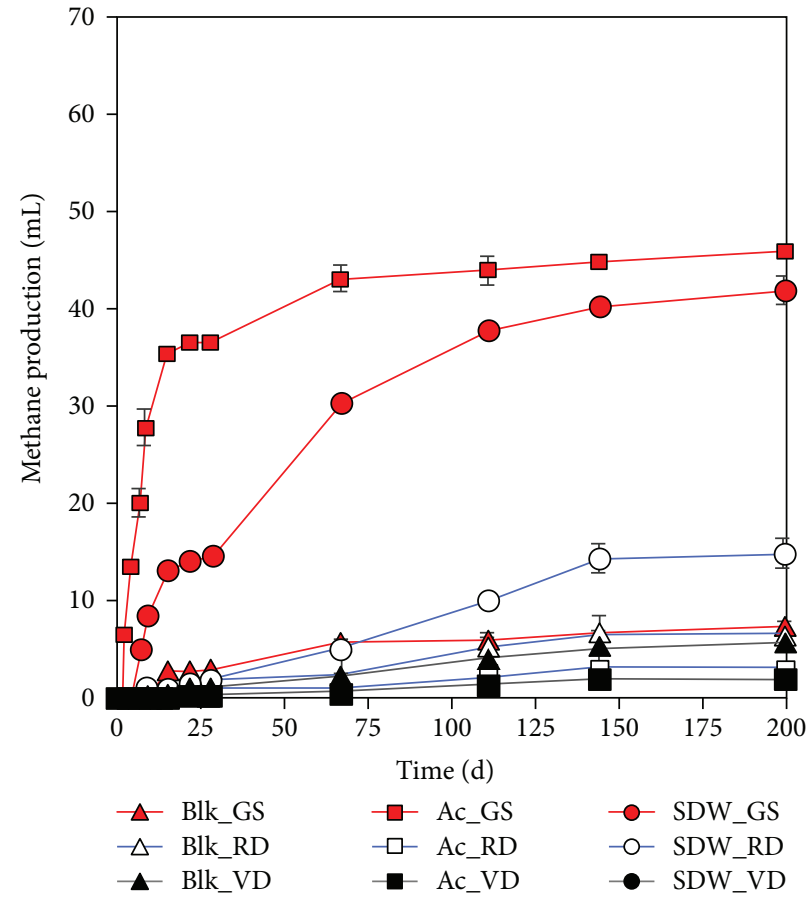

(b)

Figure 1: Methane production $(\mathrm{mL})$ at (a) $20^{\circ} \mathrm{C}$ and (b) $10^{\circ} \mathrm{C}$ from different inocula (GS: granular sludge; RD: Rahola Digestate; VD: Viinikanlahti Digestate) incubated with no substrate (Blk), acetate (Ac), and synthetic dairy wastewater (SDW).

TABLE 4: Lag phase, maximum methane production rate, and methane yield with granular sludge and the municipal digester sludges from SDW and acetate in batch assays at 10 and $20^{\circ} \mathrm{C}$.

\begin{tabular}{|c|c|c|c|c|c|c|c|c|c|c|}
\hline \multirow{2}{*}{ Temperature $\left({ }^{\circ} \mathrm{C}\right)$} & \multirow{2}{*}{ Substrate } & \multicolumn{3}{|c|}{ Lag phase $(\lambda, \mathrm{d})$} & \multicolumn{3}{|c|}{$\begin{array}{l}\text { Maximum methane production rate } \\
\qquad\left(R_{\mathrm{m}}, \mathrm{mL}-\mathrm{CH}_{4} / \mathrm{d}\right)\end{array}$} & \multicolumn{3}{|c|}{ Methane yield (\%) } \\
\hline & & GS & $\mathrm{RD}$ & VD & GS & $\mathrm{RD}$ & VD & GS & $\mathrm{RD}$ & $\mathrm{VD}$ \\
\hline \multirow{2}{*}{20} & Acetate & 0 & 8.9 & 18.1 & $9.7 \pm 6.1$ & $1.01 \pm 0.09$ & $0.7 \pm 0.05$ & $89 \pm 6$ & $81 \pm 3$ & $84 \pm 9$ \\
\hline & SDW & 0 & 4 & 51.1 & $1.3 \pm 0.7$ & $0.77 \pm 0.13$ & $1.4 \pm 0.4$ & $76 \pm 6$ & $72 \pm 3$ & $67 \pm 8$ \\
\hline \multirow{2}{*}{10} & Acetate & 0.75 & 20.1 & 21.7 & $3.5 \pm 1.15$ & $0.02 \pm 0.01$ & $0.03 \pm 0.01$ & $93 \pm 2$ & $<1$ & $<1$ \\
\hline & SDW & 1.5 & 22.9 & 20.9 & $0.6 \pm 0.2$ & $0.13 \pm 0.02$ & $0.02 \pm 0.01$ & $82 \pm 3$ & $19 \pm 4$ & $<1$ \\
\hline
\end{tabular}

digester sludges at $10^{\circ} \mathrm{C}$ (total VFAs of $290-780 \mathrm{mg} / \mathrm{L}$ with SDW and 760-1070 $\mathrm{mg} / \mathrm{L}$ with acetate). With SDW, the most abundant VFA was acetate $(110-580 \mathrm{mg} / \mathrm{L})$, and in the acetate-fed assays, only acetate (760-1070 mg/L) was found (Figure 2), which suggests an inhibition of acetotrophic activity. COD balance (Figure 3 ) shows that $9-19 \%$ and $19-23 \%$ of the sCOD (non-VFA) remained in the acetate and SDW assays, respectively, after the $200 \mathrm{~d}$ period. This non-VFA sCOD might have been produced due to the release of endogenous decay products. The unaccounted COD in the acetate and SDW assays increased at $10^{\circ} \mathrm{C}$ compared to $20^{\circ} \mathrm{C}$ (Figure 3 ) likely due to cell growth or substrate sorption to the biomass. The VFA accumulation did not affect the $\mathrm{pH}$ and was 6.9-7.1 in all the assays at 20 and $10^{\circ} \mathrm{C}$ at the end of the experiment.

The methane production from acetate or SDW with GS at 20 and $10^{\circ} \mathrm{C}$ indicates that the COD from the carbohydrate (lactose), protein (casein), and LCFA (saturated and unsaturated) fractions was metabolized by the anaerobic consortia in GS (Figure 3). On the contrary, the decrease in temperature diminished methanogenesis in $\mathrm{RD}$ and $\mathrm{VD}$ assays. Moreover, at $10^{\circ} \mathrm{C}$, the fraction of SDW hydrolyzed (sum of the VFA-COD and the $\mathrm{CH}_{4}$-COD in Figure 3) was $<50 \%$, indicating that the hydrolysis and acidification of carbohydrate and protein fractions were also diminished at $10^{\circ} \mathrm{C}$. Even in the acetate-fed assays at $10^{\circ} \mathrm{C}$, less than $50 \%$ of the substrate uptake was detected in RD and VD assays. The presence of high hydrogen partial pressures limits the syntrophic LCFA degradation by $\beta$-oxidation, and LCFA further inhibits the trophic groups in anaerobic microbial consortia, which could have affected the SDW uptake at $10^{\circ} \mathrm{C}$. However, substrate uptake (acetate and SDW) at $10^{\circ} \mathrm{C}$ was not energetically limited by hydrogen accumulation/increased hydrogen partial pressure in $\mathrm{RD}$ and $\mathrm{VD}$, as hydrogen was not found in the gas phase. Therefore, the lack of substrate uptake was related to the inhibition in acetotrophic activity in the digestate inocula at $10^{\circ} \mathrm{C}$. 


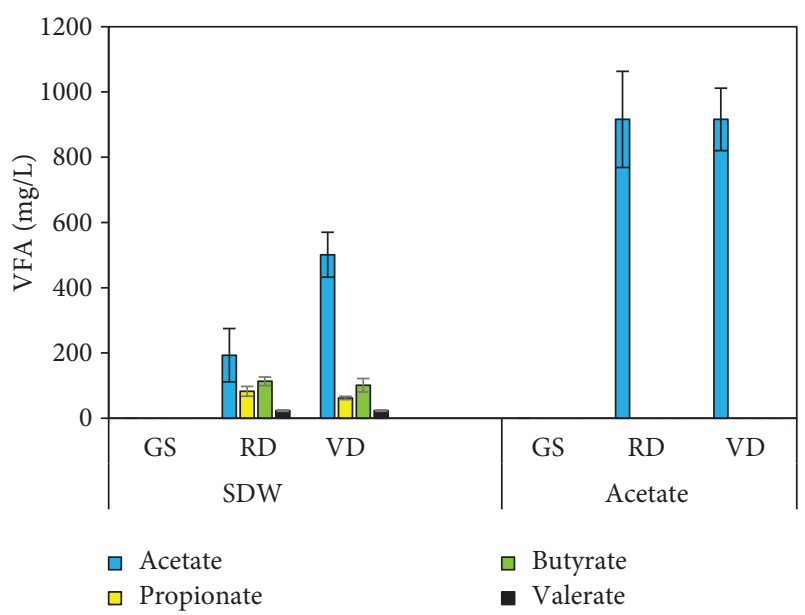

Figure 2: Residual volatile fatty acid (VFA) concentration at $10^{\circ} \mathrm{C}$ with synthetic dairy wastewater (SDW) and acetate at the end of the $200 \mathrm{~d}$ experiment (GS: granular sludge; RD: Rahola Digestate; VD: Viinikanlahti digestate).

Previously, single LCFAs-linoleic acid $(30 \mathrm{mg} / \mathrm{L})$, oleic acid $(30 \mathrm{mg} / \mathrm{L})$, and stearic acid $(10 \mathrm{mg} / \mathrm{L})$ - have been reported to inhibit methanogenesis from $100 \mathrm{mg} / \mathrm{L}$ of acetate at $21^{\circ} \mathrm{C}[18,19]$. In this study, however, a combination of LCFAs $(34.7 \mathrm{mg} / \mathrm{L}$ of linoleate, $91.2 \mathrm{mg} / \mathrm{L}$ of oleate, and $33.8 \mathrm{mg} / \mathrm{L}$ of stearate) present in SDW was converted to methane by GS at 20 and $10^{\circ} \mathrm{C}$ and by the two municipal digester sludges at $20^{\circ} \mathrm{C}$ (Figure 1). In spite of a higher LCFA load in the current experiment ( $38 \mathrm{mg}$ LCFA/g.VS) than the inhibitory concentration reported elsewhere with a single LCFA $\left(20 \mathrm{mg} \mathrm{LCFA} / \mathrm{g} \cdot \mathrm{VS}\right.$ and $6.67 \mathrm{mg}$ LCFA/g.VS at $21^{\circ} \mathrm{C}$ $[18,19])$, methane was produced from a mixture of saturated and unsaturated LCFAs in this study. To the best of our knowledge, this is the first report of methane production from a LCFA mixture containing unsaturated LCFAs (oleate and linoleate) at $10^{\circ} \mathrm{C}$, wherein the methane production was driven by the inoculum origin. These results can be used for understanding and developing anaerobic processes for the low-temperature treatment and methane production from lipid-containing wastewaters.

\subsection{Effect of Low Temperature and SDW on Microbial Community Composition}

3.3.1. Microbial Community Diversity after 200 Days. Due to the differences in the relative abundance of the microbial community composition in the three inocula, and the differing methane production in the assays at different temperatures and substrates, an underlying shift in the bacterial and archaeal taxa was envisaged after the $200 \mathrm{~d}$ incubation period. High-throughput amplicon sequencing was used to investigate the microbial community composition in the assays after 200 days. A total of 12326 OTUs were found, of which $99.9 \%$ of the microbial community belonged to 127 OTUs consisting of 33 bacterial and 4 archaeal classes. Therefore, a small portion of the taxa ( $0.01 \%$ of total OTUs) comprised a $99.9 \%$ portion of the microbial community. Moreover, similar to their inoculum, even after the $200 \mathrm{~d}$, the municipal digester sludges (RD and VD) had a higher microbial diversity (Chaol: 106-116, Shannon: 4.31-5.13) compared to the GS (Chao1: 93, Shannon: 3.69, observed_otus: 79) (Table 3). Based on the Chaol and the number of observed OTUs, the community diversity increased in VD and RD but decreased in GS during the 200-day period, independent of the temperature or the substrate.

3.3.2. Relative Abundance of the Archaeal Classes after 200 Days. The bacterial and archaeal taxa that changed with the substrate and temperature after the $200 \mathrm{~d}$ incubation period were assessed by their change in relative abundance. Only the OTUs with relative abundance above $0.1 \%$ are further discussed. In all the assays, 9 archaeal OTUs were found belonging to Methanobacteria (3 OTUs), Methanomicrobia (3 OTUs), Thermoplasmata (1 OTU), and WCHA1-57 (2 OTUs). The class Methanobacteria was found at a higher relative abundance in the GS assays (13-19\%) compared to VD and $\mathrm{RD}$ (less than 7\%) (Figure 4), but its relative abundance decreased over the incubation period compared to the GS inoculum (21\%) bearing no temperature-specific or substrate-specific trends. The class Methanomicrobia was found in all the assays after the $200 \mathrm{~d}$ incubation, with a higher relative abundance in GS $(22-28 \%$, increased from $19 \%$ ) compared to VD (increased from $13 \%$ to $19-23 \%$ at $10^{\circ} \mathrm{C}$ ) and $\mathrm{RD}$ (increased from $8 \%$ to $15-20 \%$ at $20^{\circ} \mathrm{C}$ ) (Figure 4). Within the class Methanomicrobia, the relative abundance of the hydrogenotrophic Methanolinea increased in the GS (0.8-6.5\% vs. $0.3 \%$ in inoculum), while the hydrogenotrophic ARC26 (ambiguous taxon) had a higher relative abundance in VD and RD (0.1-2\%) than in GS (Figure 5). Methanosaeta was the only acetoclastic archaeal genus found after the 200 days, and its relative abundance increased at $20^{\circ} \mathrm{C}$ in the acetate-fed assays compared to blank assays in GS (from 20 to 25\%), VD (from 8.3 to $9.1 \%$ ), and RD (from 5.1 to $13.8 \%$ ). At $10^{\circ} \mathrm{C}$, in the acetate-fed assays, the relative abundance of Methanosaeta remained high in GS (20-22\%) and increased only in VD (from 11 to 24\%) (Figure 5). The members of the class Methanobacteria and Methanomicrobia have previously been detected in psychrophilic environments [69] and in anaerobic LCFA degradation assays [70] and were also found to be prevalent in this study.

VFA accumulation (predominantly acetate) was observed with $\mathrm{RD}$ and $\mathrm{VD}$ assays at $10^{\circ} \mathrm{C}$ when fed with SDW. In addition, in the $\mathrm{RD}$ and $\mathrm{VD}$ assays at $10^{\circ} \mathrm{C}$ fed with acetate, only $50 \%$ of acetate was consumed with negligible methane production (Figure 3). Even with a high relative abundance of Methanosaeta (only acetoclastic taxa found in this study) in $\mathrm{VD}$ and of hydrogenotrophic taxa in $\mathrm{VD}$ and $\mathrm{RD}$ at $10^{\circ} \mathrm{C}$, negligible methane was produced in $\mathrm{RD}$ and $\mathrm{VD}$ assays at $10^{\circ} \mathrm{C}$. This inhibition of acetotrophic activity at $10^{\circ} \mathrm{C}$ in $\mathrm{RD}$ and VD assays suggests acetate uptake by syntrophic acetate-oxidizing bacteria (SAOB). SAOB growth can be energetically feasible at lower temperatures close to the thermodynamic equilibrium, and their presence has been confirmed at temperatures as low as $7^{\circ} \mathrm{C}$ [71-73]. SAOB are slow-growing and have been isolated in the presence of strong selection pressures $[74,75]$. In our study, the 


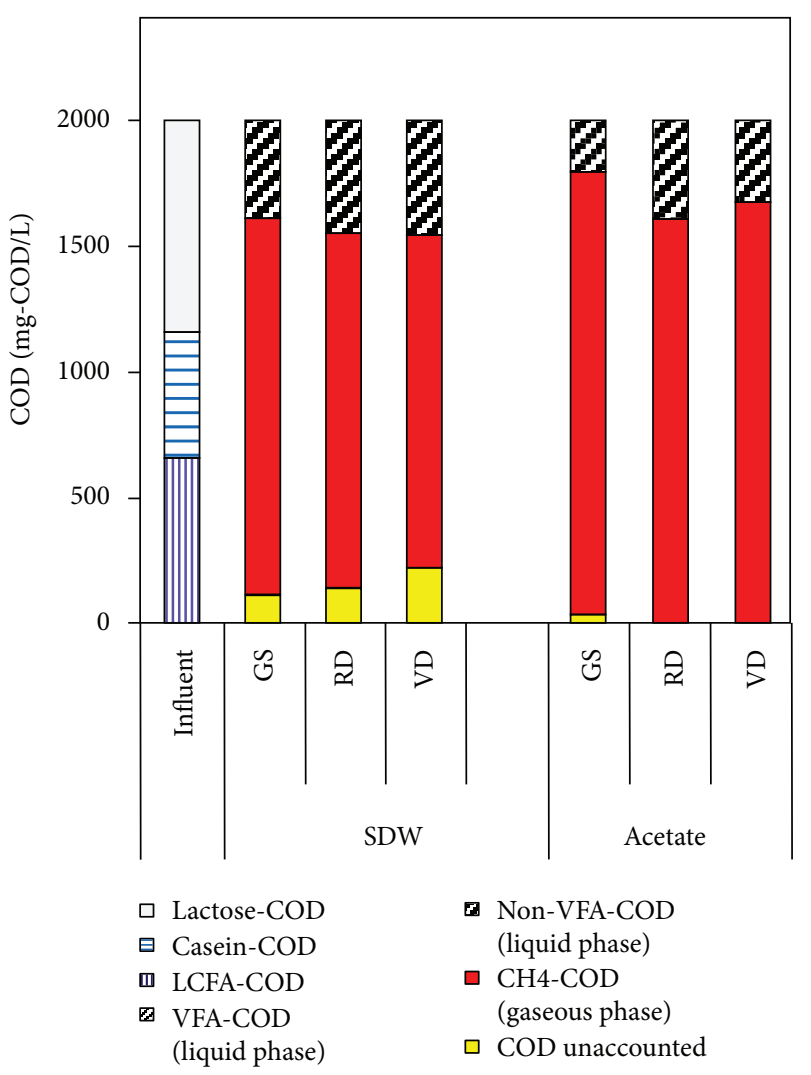

(a)

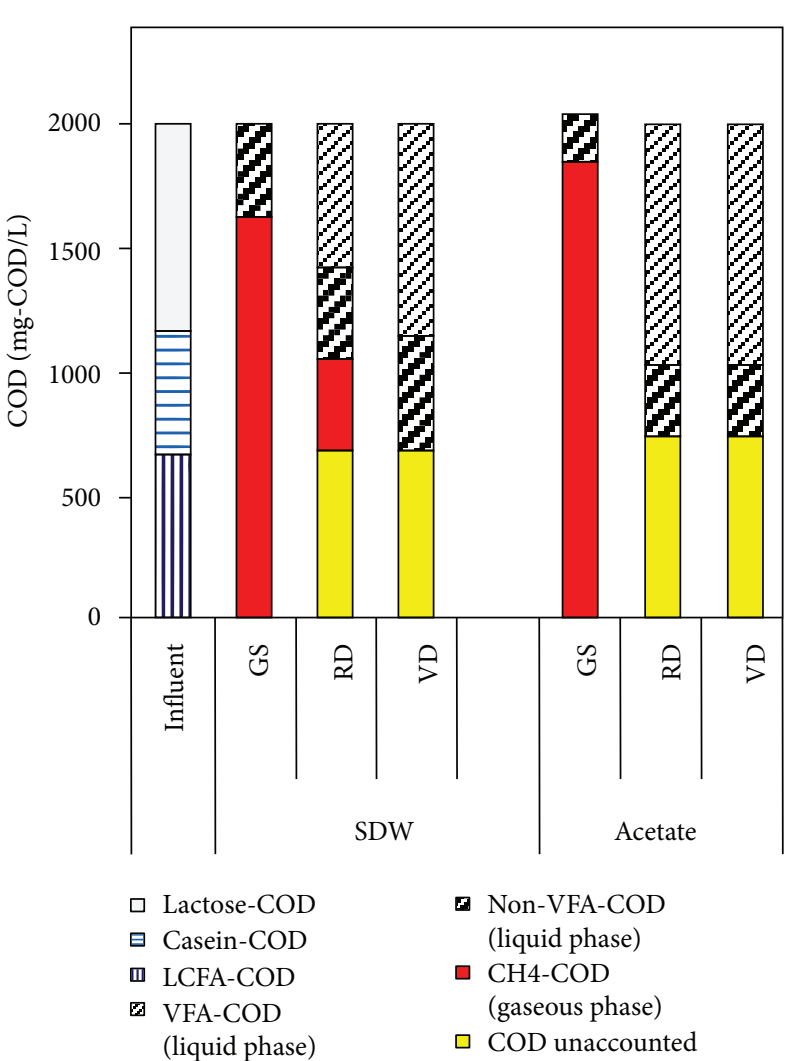

(b)

Figure 3: Mass balance of COD at (a) $20^{\circ} \mathrm{C}$ and (b) $10^{\circ} \mathrm{C}$ in the assays with different inocula (GS: granular sludge; RD: Rahola Digestate; VD: Viinikanlahti digestate) and with the substrate synthetic dairy wastewater (SDW) or acetate.

presence of stressors, such as low temperature, likely imparted a competitive advantage to the acetate oxidizers for acetate uptake compared to the acetoclastic methanogen, Methanosaeta. This advantage is conferred to the acetate oxidizers from syntrophic coupling with hydrogenotrophic methanogens, due to more favorable energetics of the hydrogenotrophic methanogenic pathway at lower temperatures $\left(10^{\circ} \mathrm{C}\right)$. A shift in the methanogenic pathway from acetotrophic to hydrogenotrophic has been observed previously with a temperature drop $[1,47,48]$, and LCFA presence has been known to inhibit acetoclastic methanogens more than hydrogenotrophic methanogens $[5,7]$, thereby suggesting a need for maintaining high hydrogenotrophic activity for methane production at low temperatures. In contrast to the previous studies at low temperatures, this study highlights the need for maintaining high acetotrophic activity for LCFA utilization at low temperatures through methanogenic archaea and/or syntrophic acetate oxidation bacteria (SAOB) (further discussed in Section 3.3.3).

3.3.3. Relative Abundance of the Bacterial Classes after 200 Days. In all the assays, the bacterial classes Anaerolineae (relative abundance 2.4-20\%), Clostridia (0.1-0.7\%), and Synergistia (6-33\%) were found at the end of the batch incubation. The classes Bacteroidia and Actinobacteria were present in higher abundance in both municipal digester sludges than in GS (Bacteroidia $15-26 \%$ vs. $<1 \%$, respectively, and
Actinobacteria $1-9 \%$ vs. $<0.1 \%$, respectively), while GS had a higher relative abundance of uncultured Aminicenantes (15-22\% vs. $0.2-1.4 \%)$ and Deltaproteobacteria (5-14\% vs. $0.2-2.8 \%$ ) (Figure 4). The large variation in relative abundance of different classes is due to the changes in temperature and substrate and are discussed below.

After the $200 \mathrm{~d}$ incubation period, 6 OTUs were found in the class Deltaproteobacteria, among which 4 belonged to the order Syntrophobacterales (families Syntrophaeceae (3 OTUs), Syntrophobacteraceae (1 OTU)) and two to the order Desulfuromonadales (family Geobacteraceae) (Figure 6). The relative abundance of the acetogenic bacterium Syntrophusand of an uncultured taxon (from family Syntrophaceae) increased in the GS at $10^{\circ} \mathrm{C}$ (from 3.3\% to 9.6-12.3\%) during the $200 \mathrm{~d}$ incubation (Figure 6), highlighting the role of the acetogenic bacteria from the family Syntrophaceae in LCFA degradation at $10^{\circ} \mathrm{C}$. The members of the family Syntrophaceae are known to degrade the saturated LCFAs-palmitate (C16:0) [65], stearate (C18:0), and heptanoate (C17:0) - at mesophilic conditions [66], and only one known species from the family Syntrophaceae-Syntrophus aciditrophicus-has been found to degrade two saturated LCFAs (palmitate (C16:0) and stearate (C18:0)) [76]. Syntrophus aciditrophicus has a growth range at temperatures of $25-42^{\circ} \mathrm{C}$; thus, a psychrotolerant growth mode at $10^{\circ} \mathrm{C}$ of Syntrophus-like taxa for metabolizing the unsaturated LCFAs (oleate and linoleate) is found in this study. 


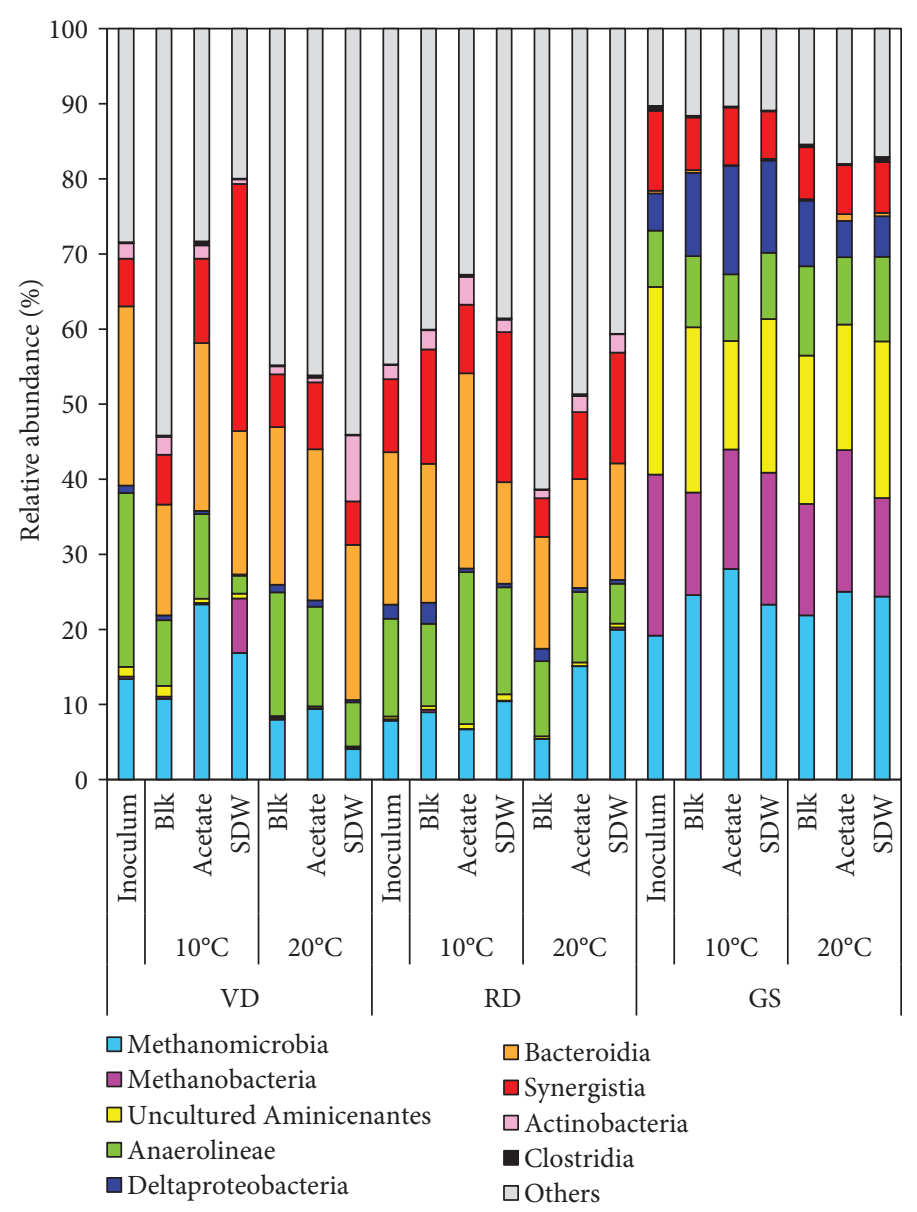

FIGURE 4: Relative abundance (\%) of the bacterial and archaeal classes found in the $16 \mathrm{~S}$ rRNA amplicon libraries in the samples during the 200 d experimental period from different inocula (GS: granular sludge; RD: Rahola Digestate; VD: Viinikanlahti Digestate) incubated at $10^{\circ} \mathrm{C}$ and $20^{\circ} \mathrm{C}$ with no substrate (Blk), acetate, and synthetic dairy wastewater (SDW). Detailed information on the sample names is shown in Table S1.

Furthermore, at $10^{\circ} \mathrm{C}$, the GS had a methane yield of $82 \%$ from the substrate SDW (Table 2) that constituted of 33\% LCFAs (18\% unsaturated LCFAs (C18:2, C18:1) and 15\% saturated LCFAs (C16:0, C18:0)). Therefore, this study confirms the possibility of methane production from the saturated and unsaturated $\mathrm{C} 16$ and $\mathrm{C} 18$ acids at low temperatures (10 and $20^{\circ} \mathrm{C}$ ) with a crucial role played by syntrophs and acetotrophs. While the metabolic pathways involved in the degradation of saturated and unsaturated LCFAs individually and in mixture at low temperatures are not known yet, they should be elucidated with further studies.

Another important class Synergistia (16 OTUs) was found in all the samples (6.3-10.6\%) (Figure 4). Although the precise function of Synergistia in degrading LCFA remains unconfirmed, it has been found in the core microbiome of mesophilic and thermophilic LCFA-fed digesters [70]. Of the 16 OTUs found in this study in the class Synergistia, 5 belonged to the thermophilic or mesophilic amino acid-degrading genera Thermovirga [77], Lactivibrio [78], or Aminivibrio [79]. As casein constituted 25\% COD in the $\mathrm{SDW}$, the presence of amino-acid degraders is expected; however, few of the other 11 Synergistia taxa could have a role in methane production from SDW.
In GS, Aminicenantes clustered closely with the hydrogenotrophic Methanobacteriales (Figure 7). Additionally, Synergistetes was found in a high relative abundance in $\mathrm{RD}$ and VD assays, and a recently found thermophilic SAOB, Gelria (order Thermoanaerobacterales) [80], was found in a GS assay when fed with SDW at $20^{\circ} \mathrm{C}$. The taxa from Aminicenantes, Synergistetes, and uncultured Gelria are putative SAOBs in this study due to their capacity and known role in syntrophic acetate oxidation $[73,80,81]$. However, as these species are uncultured, their specific functions cannot be confirmed. While syntrophic electron transfer by Aminicenantes has been suggested previously in a stratified lake at a low temperature of $7^{\circ} \mathrm{C}$ [73], the Synergistetes have been shown to perform syntrophic acetate oxidation with Methanoculleus and Methanosarcina in mesophilic anaerobic reactors [81]. Moreover, Geobacter (2 OTUs) were also enriched in GS assays at $10^{\circ} \mathrm{C}$ with concurrent high relative abundance of Methanosaeta in acetate and SDW assays. As Geobacter species can facilitate syntrophic electron transfer with Methanosaeta [82], there is also a possibility for Geobacter-mediated syntrophic acetate oxidation in this study. Furthermore, Smithella was found in the municipal digester sludges but not in GS and could have played a role in the 


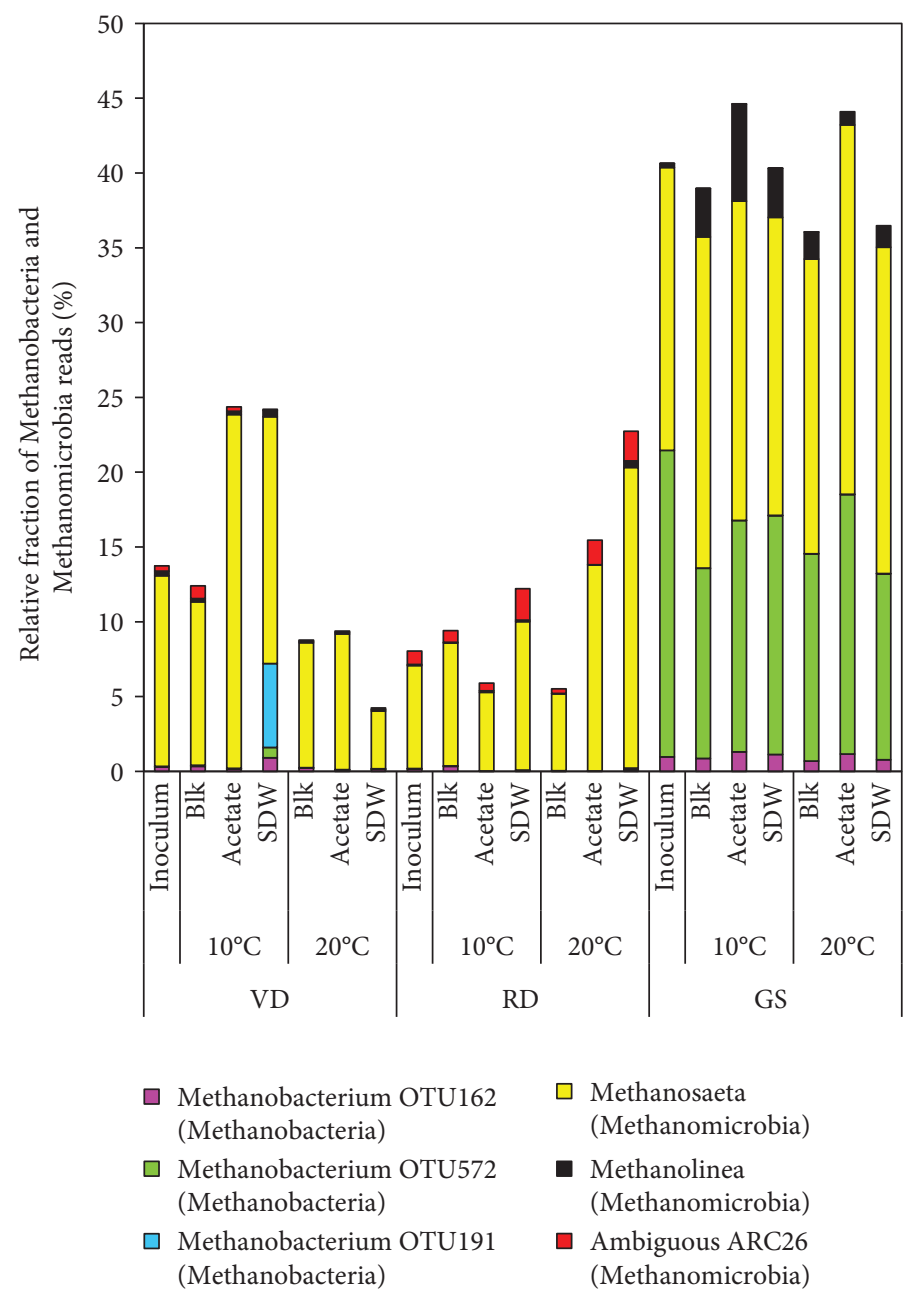

FIGURE 5: Relative fraction (\%) of the archaeal genera belonging to the classes Methanobacteria and Methanomicrobia found in the 16S rRNA amplicon libraries in the samples during the $200 \mathrm{~d}$ experimental period from different inocula (GS: granular sludge; RD: Rahola Digestate; VD: Viinikanlahti Digestate) incubated at $10^{\circ} \mathrm{C}$ and $20^{\circ} \mathrm{C}$ with no substrate (Blk), acetate, and synthetic dairy wastewater (SDW). Classes are mentioned within brackets. Detailed information on the sample names is shown in Table S1.

LCFA degradation in SDW at $20^{\circ} \mathrm{C}$ due its known role in syntrophic acetate oxidation at $22^{\circ} \mathrm{C}[83]$. As the number of $\mathrm{SAOB}$ candidates has been increasing recently and many SAOB taxa remain unknown, the possibility of SAOB at lower temperatures in this study cannot be excluded. Advanced molecular techniques, such as metagenomics, along with quantitative methods like qPCR are required to evaluate the activity and functional role of Syntrophus and Syntrophus-like taxa in degrading the unsaturated and saturated LCFAs (palmitate, stearate, oleate, and linoleate) and for the identification of putative SAOB for syntrophic interspecies electron transfer at low temperatures of $20^{\circ} \mathrm{C}$ and $10^{\circ} \mathrm{C}$.

3.3.4. Patterns in Microbial Community. The clustering of the microbial samples from different assays after $200 \mathrm{~d}$ was represented through dendrograms on a shade plot and principal coordinate analysis ( $\mathrm{PCoA}$ ) to discern patterns in the microbial community (Figures 7 and S2). The PCoA analysis revealed that the first two axes explained approximately $80 \%$ (first axis $72.5 \%$ and second axis $9 \%$ ) of the variation in the microbial community present in the VD, RD, and GS sludges (Fig. S2). Both the dendrograms in the shade plot and the similarity \% in the PCoA plot show that the microbial community compositions in RD and in VD were similar to each other and clustered closely at $70 \%$ similarity in the blank and acetate, and SDW-fed assays. But the microbial community compositions of assays (blank, acetate, or SDW-fed) with GS inoculum had a higher similarity among themselves (85\%) and clustered further from the RD and VD (Fig. S2), to which the GS shared a lower similarity (66\% with RD and VD) (Figure 7).

This clustering indicates that even after a prolonged incubation time of 200 days at a specific selection pressure (of temperature and substrate), the composition of the microbial communities did not converge. The only instance where an overlap in microbial classes was found between assays of different inoculum types was with the acetate-fed municipal digester sludges at $20^{\circ} \mathrm{C}$ (Figures 7 and S2). This suggests the effect of acetate in converging the microbial communities in $\mathrm{VD}$ and $\mathrm{RD}$, although even the initial microbial community composition of $\mathrm{VD}$ and $\mathrm{RD}$ was similar. A continuous 


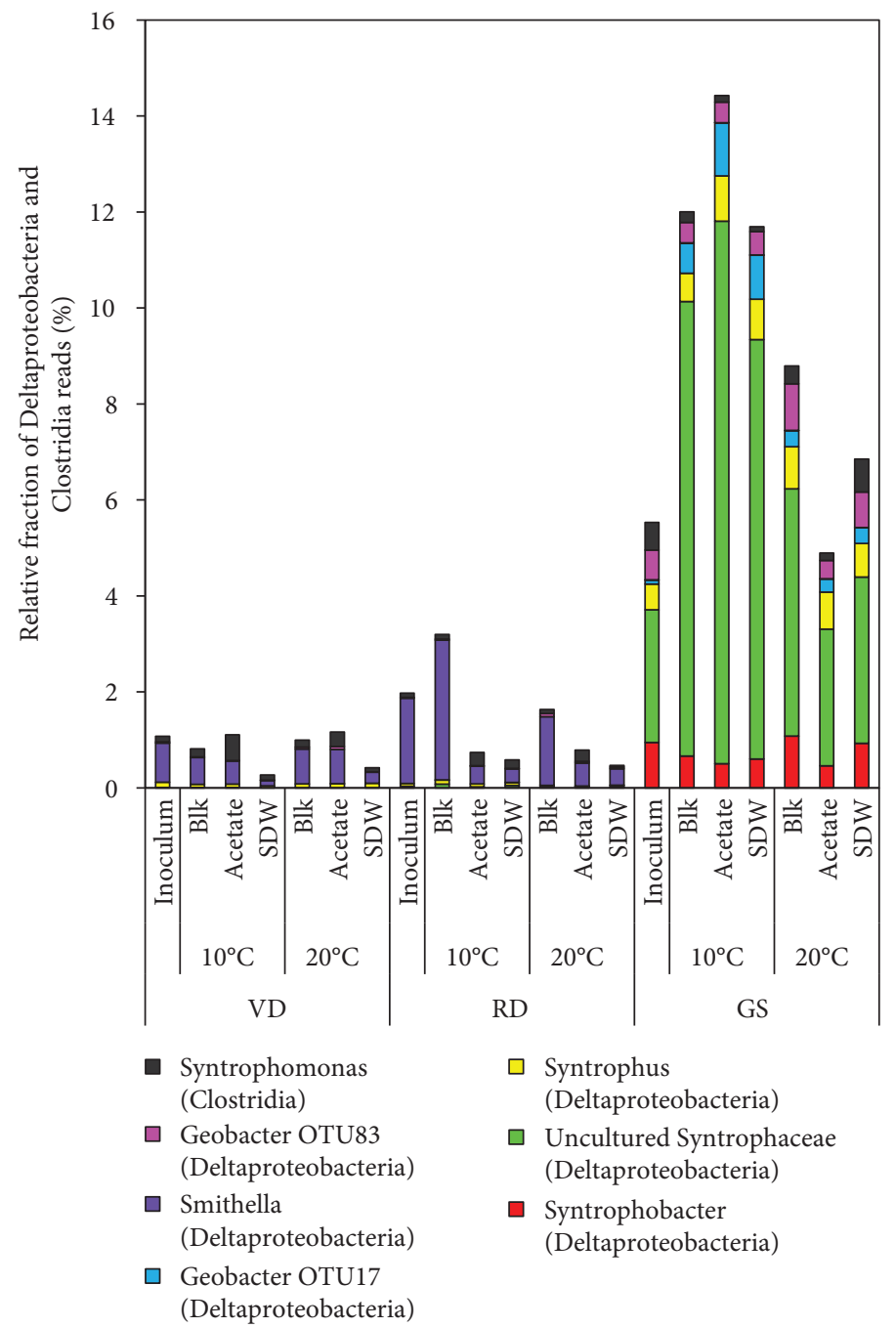

FIGURE 6: Relative fraction (\%) of the bacterial genera belonging to the classes Deltaproteobacteria and Clostridia found in the 16S rRNA amplicon libraries in the samples during the $200 \mathrm{~d}$ experimental period from different inocula (GS: granular sludge; RD: Rahola Digestate; VD: Viinikanlahti Digestate) incubated at $10^{\circ} \mathrm{C}$ and $20^{\circ} \mathrm{C}$ with no substrate (Blk), acetate, and synthetic dairy wastewater (SDW). Classes are mentioned within brackets. Detailed information on the sample names is shown in Table S1.

reactor operation may further reveal the development of microbial community assembly occurring under strong selection pressures in various inocula considering their dissimilar microbial composition. The similar performance (methane production) obtained with acetate or SDW with the three inocula at $20^{\circ} \mathrm{C}$, irrespective of the differences in initial microbial community composition, suggests that functions were conserved in $\mathrm{VD}, \mathrm{RD}$, and $\mathrm{GS}$ at $20^{\circ} \mathrm{C}$. However, this functional conservation was not effective at $10^{\circ} \mathrm{C}$ due to the strong abrupt selection pressures that hindered the metabolic functions and thus the methane production at $10^{\circ} \mathrm{C}$ compared to $20^{\circ} \mathrm{C}$.

The presence of syntrophic partners (acetogenic bacteria with methanogenic archaea) is crucial for the LCFA degradation and was evaluated through their cooccurrence through the dendrograms. The OTU clustering showed that the bacterial classes Synergistia and Anaerolineae grouped with the archaeal class Methanomicrobia (the cluster was present in all samples) and conferred functional conservation to VD,
$\mathrm{RD}$, and GS at $20^{\circ} \mathrm{C}$. Additionally, in GS, the bacterial classes Deltaproteobacteria and uncultured Aminicenantes grouped with the archaeal class Methanobacteria (the cluster present only in GS) (Figure 7), which is indicative of functional redundancy in GS that was not present in the RD and VD. As optimal metabolite transfer is aided by close proximity between syntrophic partners $[84,85]$, the formation of the distinct clusters in this study (Figure 7) signifies structural proximity at a molecular level and indicates an underlying interactive functional role and putative ecological niche associations. Previously, Grabowski et al. [66] had demonstrated the formation of close spatial associations of acetogens from Deltaproteobacteria (Syntrophus-related) with the methanogenic archaea-Methanocalculus and Methanosaeta-using in situ hybridization. In our study, the close clustering of Deltaproteobacteria and Methanobacteria in the GS could have facilitated the degradative capacity and the methane production with GS. An investigation using highthroughput sequencing (metagenomics) of closely clustered 


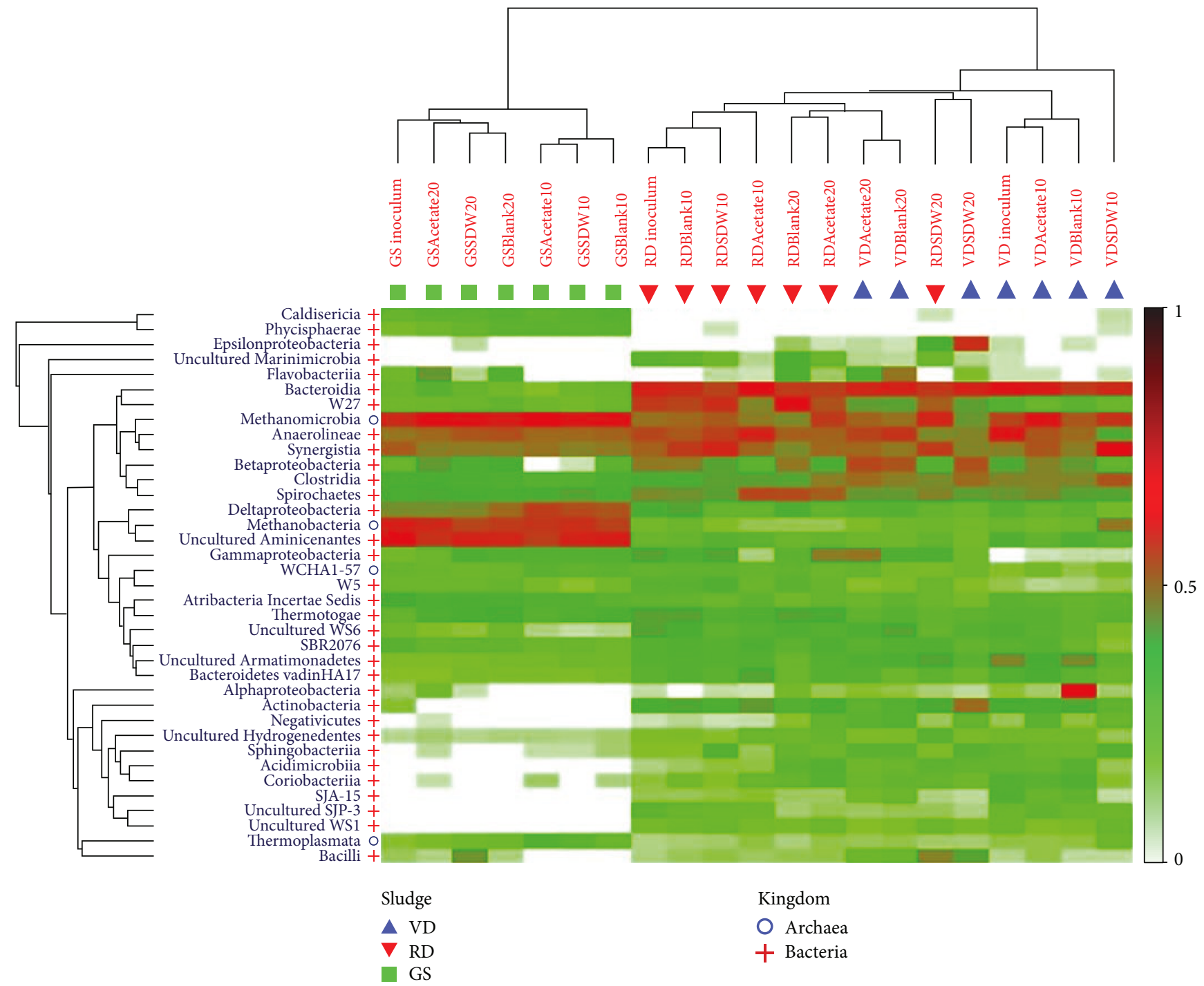

FIgURE 7: Heat map showing the clustering and relative abundance of the bacterial and archaeal classes that formed $99.9 \%$ of the microbial community in the assays inoculated with VD, RD, and GS and fed with no substrate (blank), acetate, or synthetic dairy wastewater (SDW) at $10^{\circ} \mathrm{C}$ and $20^{\circ} \mathrm{C}$. Symbols + and o indicate the kingdom bacteria and archaea, respectively, on the y-axis. Symbols $\boldsymbol{\Delta}, \boldsymbol{\nabla}$, and $\boldsymbol{\square}$ represent the inoculum used in the assays as VD, RD, and GS, respectively, on the $\mathrm{x}$-axis. Detailed information on the sample names is shown in Table S1.

taxa involving bacterial acetogens and methanogenic archaea (such as Methanomicrobia with Synergistia and Methanobacteria with Deltaproteobacteria in this study) could confirm the functional role of the syntrophic partners involved in the clusters.

\section{Conclusions}

For the first time, the anaerobic conversion of mixed LCFA (saturated as well as mono- and polyunsaturated) containing wastewater (SDW) to methane is demonstrated at low temperatures of 20 and $10^{\circ} \mathrm{C}$. High-throughput amplicon sequencing revealed the crucial roles of the acetotrophic activity by Methanosaeta and putative SAOB and of the psychrotolerant bacteria from the family Syntrophaceae (Syntrophus and uncultured taxa) in LCFA degradation at $10^{\circ} \mathrm{C}$. Unacclimated granular sludge achieved high methane yields
(70-85\%) with SDW and was found to be a suitable inoculum for the treatment of mixed LCFA containing wastewater at both 20 and $10^{\circ} \mathrm{C}$. Unacclimated municipal digester sludges can be employed for treating the mixed-LCFA containing wastewaters at $20^{\circ} \mathrm{C}$ but not at lower temperatures. This study provides the basis for the inoculum selection by the evaluation of acetotrophic activity and the initial microbial community characteristics for producing methane from mixed LCFA-containing wastewater at low temperatures (up to $10^{\circ} \mathrm{C}$ ).

\section{Data Availability}

The 16S rRNA sequences used to support the findings of this study have been deposited in the NCBI Sequence Read Archive under project SRP164945. 


\section{Disclosure}

Riitta Kettunen's present address is Tampere Water, 33800 Tampere, Finland.

\section{Conflicts of Interest}

The authors declare that they have no conflicts of interest.

\section{Acknowledgments}

The authors thank the Viinikanlahti and Rahola municipal wastewater treatment plants (Tampere, Finland) for the municipal digester sludges. This project has received funding from the European Union's Horizon 2020 research and innovation programme under the Marie Sklodowska-Curie European Joint Doctorate (EJD) in Advanced Biological Waste-To-Energy Technologies (ABWET), under grant agreement No 643071.

\section{Supplementary Materials}

Fig. S1: soluble COD (sCOD) removal and methane yield from acetate or synthetic dairy wastewater (SDW) at (a) $20^{\circ} \mathrm{C}$ and (b) $10^{\circ} \mathrm{C}$ with different inocula (GS: granular sludge; RD: Rahola Digestate; VD: Viinikanlahti digestate). Fig. S2: principle coordinate analysis (PCoA) plot of the bacterial and archaeal classes that formed $99.9 \%$ of the microbial community in the assays inoculated with $\mathrm{VD}, \mathrm{RD}$, and $\mathrm{GS}$ and fed with no substrate (blank), acetate, and synthetic dairy wastewater $(\mathrm{SDW})$ at $10^{\circ} \mathrm{C}$ and $20^{\circ} \mathrm{C}$. Solid line and dashed line indicate similarity among the samples at 70 and $85 \%$. Table S1: detailed information on the sample names used in the multivariate analysis plots. (Supplementary Materials)

\section{References}

[1] G. Lettinga, S. Rebac, and G. Zeeman, "Challenge of psychrophilic anaerobic wastewater treatment," Trends in Biotechnology, vol. 19, no. 9, pp. 363-370, 2001.

[2] B. Faye and G. Konuspayeva, "The sustainability challenge to the dairy sector - the growing importance of non-cattle milk production worldwide," International Dairy Journal, vol. 24, no. 2, pp. 50-56, 2012.

[3] D. Karadag, O. E. Koroglu, B. Ozkaya et al., "Anaerobic granular reactors for the treatment of dairy wastewater: a review," International Journal of Dairy Technology, vol. 68, no. 4, pp. 459-470, 2015.

[4] M. Perle, S. Kimchie, and G. Shelef, "Some biochemical aspects of the anaerobic degradation of dairy wastewater," Water Research, vol. 29, no. 6, pp. 1549-1554, 1995.

[5] M. M. Alves, M. A. Pereira, D. Z. Sousa et al., "Waste lipids to energy: how to optimize methane production from long-chain fatty acids (LCFA)," Microbial Biotechnology, vol. 2, no. 5, pp. 538-550, 2009.

[6] I. W. Koster and A. Cramer, "Inhibition of methanogenesis from acetate in granular sludge by long-chain fatty acids," Applied and Environmental Microbiology, vol. 53, no. 2, pp. 403-409, 1987.
[7] J. Lalman and D. M. Bagley, "Effects of C18 long chain fatty acids on glucose, butyrate and hydrogen degradation," Water Research, vol. 36, no. 13, pp. 3307-3313, 2002.

[8] H.-S. Shin, S.-H. Kim, C.-Y. Lee, and S.-Y. Nam, "Inhibitory effects of long-chain fatty acids on VFA degradation and $\beta$-oxidation," Water Science \& Technology, vol. 47, no. 10, pp. 139-146, 2003.

[9] J. A. Lalman and I. Komjarova, "Impact of long chain fatty acids on glucose fermentation under mesophilic conditions," Environmental Technology, vol. 25, no. 4, pp. 391-401, 2004.

[10] J. L. Chen, R. Ortiz, T. W. J. Steele, and D. C. Stuckey, "Toxicants inhibiting anaerobic digestion: a review," Biotechnology Advances, vol. 32, no. 8, pp. 1523-1534, 2014.

[11] D. B. Nedwell, "Effect of low temperature on microbial growth: lowered affinity for substrates limits growth at low temperature," FEMS Microbiology Ecology, vol. 30, no. 2, pp. 101-111, 1999.

[12] A. N. Nozhevnikova, K. Zepp, F. Vazquez, A. J. B. Zehnder, and C. Holliger, "Evidence for the existence of psychrophilic methanogenic communities in anoxic sediments of deep lakes," Applied and Environmental Microbiology, vol. 69, no. 3, pp. 1832-1835, 2003.

[13] D. Zhang, W. Zhu, C. Tang et al., "Bioreactor performance and methanogenic population dynamics in a low-temperature $\left(5-18^{\circ} \mathrm{C}\right)$ anaerobic fixed-bed reactor," Bioresource Technology, vol. 104, pp. 136-143, 2012.

[14] M. S. Sheldon and I. G. Erdogan, "Multi-stage EGSB/MBR treatment of soft drink industry wastewater," Chemical Engineering Journal, vol. 285, pp. 368-377, 2016.

[15] S. Connaughton, G. Collins, and V. Oflaherty, "Psychrophilic and mesophilic anaerobic digestion of brewery effluent: a comparative study," Water Research, vol. 40, no. 13, pp. 25032510, 2006.

[16] K. Bialek, D. Cysneiros, and V. O’Flaherty, "Hydrolysis, acidification and methanogenesis during low-temperature anaerobic digestion of dilute dairy wastewater in an inverted fluidised bioreactor," Applied Microbiology and Biotechnology, vol. 98, no. 20, pp. 8737-8750, 2014.

[17] S.-H. Kim, S.-K. Han, and H.-S. Shin, "Kinetics of LCFA inhibition on acetoclastic methanogenesis, propionate degradation and $\beta$-oxidation," Journal of Environmental Science and Health, Part A, vol. 39, no. 4, pp. 1025-1037, 2004.

[18] J. A. Lalman and D. M. Bagley, "Anaerobic degradation and inhibitory effects of linoleic acid," Water Research, vol. 34, no. 17, pp. 4220-4228, 2000.

[19] J. A. Lalman and D. M. Bagley, "Anaerobic degradation and methanogenic inhibitory effects of oleic and stearic acids," Water Research, vol. 35, no. 12, pp. 2975-2983, 2001.

[20] D. Daffonchio, J. Thaveesri, and W. Verstraete, "Contact angle measurement and cell hydrophobicity of granular sludge from upflow anaerobic sludge bed reactors," Applied and Environmental Microbiology, vol. 61, no. 10, pp. 36763680, 1995.

[21] M. A. Pereira, O. C. Pires, M. Mota, and M. M. Alves, "Anaerobic biodegradation of oleic and palmitic acids: evidence of mass transfer limitations caused by long chain fatty acid accumulation onto the anaerobic sludge," Biotechnology and Bioengineering, vol. 92, no. 1, pp. 15-23, 2005.

[22] K. Bialek, A. Kumar, T. Mahony, P. N. L. Lens, and V. O' Flaherty, "Microbial community structure and dynamics in anaerobic fluidized-bed and granular sludge-bed reactors: 
influence of operational temperature and reactor configuration," Microbial Biotechnology, vol. 5, no. 6, pp. 738-752, 2012.

[23] E. Petropoulos, J. Dolfing, Y. Yu et al., "Lipolysis of domestic wastewater in anaerobic reactors operating at low temperatures," Environmental Science: Water Research \& Technology, vol. 4, no. 7, pp. 1002-1013, 2018.

[24] L. Sun, T. Liu, B. Müller, and A. Schnürer, "The microbial community structure in industrial biogas plants influences the degradation rate of straw and cellulose in batch tests," Biotechnology for Biofuels, vol. 9, no. 1, 2016.

[25] R. H. Kettunen and J. A. Rintala, "The effect of low temperature $\left(5-29^{\circ} \mathrm{C}\right)$ and adaptation on the methanogenic activity of biomass," Applied Microbiology and Biotechnology, vol. 48, no. 4, pp. 570-576, 1997.

[26] A. P. Trzcinski and D. C. Stuckey, "Treatment of municipal solid waste leachate using a submerged anaerobic membrane bioreactor at mesophilic and psychrophilic temperatures: analysis of recalcitrants in the permeate using GC-MS," Water Research, vol. 44, no. 3, pp. 671-680, 2010.

[27] H. el-Kamah, A. Tawfik, M. Mahmoud, and H. Abdel-Halim, "Treatment of high strength wastewater from fruit juice industry using integrated anaerobic/aerobic system," Desalination, vol. 253, no. 1-3, pp. 158-163, 2010.

[28] S. A. Luostarinen and J. A. Rintala, "Anaerobic on-site treatment of black water and dairy parlour wastewater in UASBseptic tanks at low temperatures," Water Research, vol. 39, no. 2-3, pp. 436-448, 2005.

[29] F. R. L. Fia, A. T. Matos, A. C. Borges, R. Fia, and P. R. Cecon, "Treatment of wastewater from coffee bean processing in anaerobic fixed bed reactors with different support materials: performance and kinetic modeling," Journal of Environmental Management, vol. 108, pp. 14-21, 2012.

[30] A. M. Enright, S. McHugh, G. Collins, and V. O'Flaherty, "Low-temperature anaerobic biological treatment of solventcontaining pharmaceutical wastewater," Water Research, vol. 39, no. 19, pp. 4587-4596, 2005.

[31] S. McHugh, G. Collins, and V. O'Flaherty, "Long-term, highrate anaerobic biological treatment of whey wastewaters at psychrophilic temperatures," Bioresource Technology, vol. 97, no. 14, pp. 1669-1678, 2006.

[32] W. Xing, Y. Zhao, and J. Zuo, "Microbial activity and community structure in a lake sediment used for psychrophilic anaerobic wastewater treatment," Journal of Applied Microbiology, vol. 109, no. 5, pp. 1829-1837, 2010.

[33] C. S. Hwu, B. Donlon, and G. Lettinga, "Comparative toxicity of long-chain fatty acid to anaerobic sludges from various origins," Water Science and Technology, vol. 34, no. 5-6, pp. 351358, 1996.

[34] M. A. Pereira, O. C. Pires, M. Mota, and M. M. Alves, “Anaerobic degradation of oleic acid by suspended and granular sludge: identification of palmitic acid as a key intermediate," Water Science \& Technology, vol. 45, no. 10, pp. 139-144, 2002.

[35] M. A. Pereira, M. Mota, and M. M. Alves, "Operation of an anaerobic filter and an EGSB reactor for the treatment of an oleic acid-based effluent: influence of inoculum quality," Process Biochemistry, vol. 37, no. 9, pp. 1025-1031, 2002.

[36] C. S. Hwu, S. K. Tseng, C. Y. Yuan, Z. Kulik, and G. Lettinga, "Biosorption of long-chain fatty acids in UASB treatment process," Water Research, vol. 32, no. 5, pp. 1571-1579, 1998.
[37] R. M. Ziels, D. A. C. Beck, M. Martí, H. L. Gough, H. D. Stensel, and B. H. Svensson, "Monitoring the dynamics of syntrophic $\beta$-oxidizing bacteria during anaerobic degradation of oleic acid by quantitative PCR," FEMS Microbiology Ecology, vol. 91, no. 4, 2015.

[38] R. M. Ziels, D. Z. Sousa, H. D. Stensel, and D. A. C. Beck, "DNA-SIP based genome-centric metagenomics identifies key long-chain fatty acid-degrading populations in anaerobic digesters with different feeding frequencies," The ISME Journal, vol. 12, no. 1, pp. 112-123, 2017.

[39] L. Regueiro, M. Carballa, and J. M. Lema, "Microbiome response to controlled shifts in ammonium and LCFA levels in co-digestion systems," Journal of Biotechnology, vol. 220, pp. 35-44, 2016.

[40] J. He, X. Wang, X. Yin et al., "Insights into biomethane production and microbial community succession during semicontinuous anaerobic digestion of waste cooking oil under different organic loading rates," $A M B$ Express, vol. 8, no. 1, p. 92, 2018.

[41] D. Z. Sousa, H. Smidt, M. M. Alves, and A. J. M. Stams, "Ecophysiology of syntrophic communities that degrade saturated and unsaturated long-chain fatty acids," FEMS Microbiology Ecology, vol. 68, no. 3, pp. 257-272, 2009.

[42] D. Z. Sousa, M. A. Pereira, H. Smidt, A. J. M. Stams, and M. M. Alves, "Molecular assessment of complex microbial communities degrading long chain fatty acids in methanogenic bioreactors," FEMS Microbiology Ecology, vol. 60, no. 2, pp. 252-265, 2007.

[43] J. Palatsi, J. Illa, F. X. Prenafeta-Boldú et al., "Long-chain fatty acids inhibition and adaptation process in anaerobic thermophilic digestion: batch tests, microbial community structure and mathematical modelling," Bioresource Technology, vol. 101, no. 7, pp. 2243-2251, 2010.

[44] M. D. Seib, K. J. Berg, and D. H. Zitomer, "Influent wastewater microbiota and temperature influence anaerobic membrane bioreactor microbial community," Bioresource Technology, vol. 216, pp. 446-452, 2016.

[45] L. Regueiro, M. Carballa, and J. M. Lema, "Outlining microbial community dynamics during temperature drop and subsequent recovery period in anaerobic co-digestion systems," Journal of Biotechnology, vol. 192, pp. 179-186, 2014.

[46] A. L. Smith, S. J. Skerlos, and L. Raskin, "Anaerobic membrane bioreactor treatment of domestic wastewater at psychrophilic temperatures ranging from $15^{\circ} \mathrm{C}$ to $3^{\circ} \mathrm{C}$, Environmental Science: Water Research \& Technology, vol. 1, no. 1, pp. 56-64, 2015.

[47] R. M. McKeown, C. Scully, A.-M. Enright et al., "Psychrophilic methanogenic community development during long-term cultivation of anaerobic granular biofilms," The ISME Journal, vol. 3, no. 11, pp. 1231-1242, 2009.

[48] A.Siggins, A.-M. Enright, and V.O'Flaherty, "Low-temperature $\left(7^{\circ} \mathrm{C}\right)$ anaerobic treatment of a trichloroethylene-contaminated wastewater: microbial community development," Water Research, vol. 45, no. 13, pp. 4035-4046, 2011.

[49] O. R. Kotsyurbenko, "Trophic interactions in the methanogenic microbial community of low-temperature terrestrial ecosystems," FEMS Microbiology Ecology, vol. 53, no. 1, pp. 3-13, 2005.

[50] S. H. Kim, S. K. Han, and H. S. Shin, "Two-phase anaerobic treatment system for fat-containing wastewater," Journal of Chemical Technology \& Biotechnology, vol. 79, no. 1, pp. 6371, 2004. 
[51] R. H. Kettunen and J. A. Rintala, "Sequential anaerobicaerobic treatment of sulphur rich phenolic leachates," Journal of Chemical Technology AND Biotechnology, vol. 62, no. 2, pp. 177-184, 1995.

[52] A. J. Cavaleiro, M. A. Pereira, and M. Alves, "Enhancement of methane production from long chain fatty acid based effluents," Bioresource Technology, vol. 99, no. 10, pp. 4086-4095, 2008.

[53] W. F. Owen, D. C. Stuckey, J. B. Healy Jr., L. Y. Young, and P. L. McCarty, "Bioassay for monitoring biochemical methane potential and anaerobic toxicity," Water Research, vol. 13, no. 6, pp. 485-492, 1979.

[54] S. Yamamoto, J. B. Alcauskas, and T. E. Crozier, "Solubility of methane in distilled water and seawater," Journal of Chemical \& Engineering Data, vol. 21, no. 1, pp. 78-80, 1976.

[55] E. Breitbarth, M. M. Mills, G. Friedrichs, and J. LaRoche, "The Bunsen gas solubility coefficient of ethylene as a function of temperature and salinity and its importance for nitrogen fixation assays," Limnology and Oceanography: Methods, vol. 2, no. 8, pp. 282-288, 2004.

[56] R. I. Griffiths, A. S. Whiteley, A. G. O'Donnell, and M. J. Bailey, "Rapid method for coextraction of DNA and RNA from natural environments for analysis of ribosomal DNA- and rRNA-based microbial community composition," Applied and Environmental Microbiology, vol. 66, no. 12, pp. 54885491, 2000.

[57] J. G. Caporaso, C. L. Lauber, W. A. Walters et al., "Global patterns of 16S rRNA diversity at a depth of millions of sequences per sample," Proceedings of the National Academy of Sciences of the United States of America, vol. 108, Supplement 1, pp. 4516-4522, 2011.

[58] J. G. Caporaso, J. Kuczynski, J. Stombaugh et al., "QIIME allows analysis of high-throughput community sequencing data," Nature Methods, vol. 7, no. 5, pp. 335-336, 2010.

[59] E. Aronesty, "Comparison of sequencing utility programs," The Open Bioinformatics Journal, vol. 7, no. 1, pp. 1-8, 2013.

[60] E. Pruesse, C. Quast, K. Knittel et al., "SILVA: a comprehensive online resource for quality checked and aligned ribosomal RNA sequence data compatible with ARB," Nucleic Acids Research, vol. 35, no. 21, pp. 7188-7196, 2007.

[61] F. O. Glöckner, P. Yilmaz, C. Quast et al., "25 years of serving the community with ribosomal RNA gene reference databases and tools," Journal of Biotechnology, vol. 261, pp. 169-176, 2017.

[62] K. R. Clarke, R. N. Gorley, P. J. Somerfield, and R. M. Warwick, Change in marine communities: an approach to statistical analysis and interpretation, Primer-E Ltd, Plymouth UK, 3rd edition, 2014.

[63] R. M. Ziels, D. A. C. Beck, and H. D. Stensel, "Long-chain fatty acid feeding frequency in anaerobic codigestion impacts syntrophic community structure and biokinetics," Water Research, vol. 117, pp. 218-229, 2017.

[64] R. M. Ziels, A. Karlsson, D. A. C. Beck et al., "Microbial community adaptation influences long-chain fatty acid conversion during anaerobic codigestion of fats, oils, and grease with municipal sludge," Water Research, vol. 103, pp. 372-382, 2016.

[65] M. Hatamoto, H. Imachi, Y. Yashiro, A. Ohashi, and H. Harada, "Diversity of anaerobic microorganisms involved in long-chain fatty acid degradation in methanogenic sludges as revealed by RNA-based stable isotope probing," Applied and Environmental Microbiology, vol. 73, no. 13, pp. 41194127, 2007.

[66] A. Grabowski, D. Blanchet, and C. Jeanthon, "Characterization of long-chain fatty-acid-degrading syntrophic associations from a biodegraded oil reservoir," Research in Microbiology, vol. 156, no. 7, pp. 814-821, 2005.

[67] E. Gunnigle, J. L. Nielsen, M. Fuszard et al., "Functional responses and adaptation of mesophilic microbial communities to psychrophilic anaerobic digestion," FEMS Microbiology Ecology, vol. 91, article fiv132, 2015.

[68] A. L. Smith, S. J. Skerlos, and L. Raskin, "Psychrophilic anaerobic membrane bioreactor treatment of domestic wastewater," Water Research, vol. 47, no. 4, pp. 1655-1665, 2013.

[69] S. Wei, H. Cui, H. He, F. Hu, X. Su, and Y. Zhu, "Diversity and distribution of archaea community along a stratigraphic permafrost profile from Qinghai-Tibetan plateau, China," Archaea, vol. 2014, Article ID 240817, 11 pages, 2014.

[70] Y. M. Amha, M. Z. Anwar, A. Brower et al., "Inhibition of anaerobic digestion processes: applications of molecular tools," Bioresource Technology, vol. 247, pp. 999-1014, 2018.

[71] J. Dolfing, "Thermodynamic constraints on syntrophic acetate oxidation," Applied and Environmental Microbiology, vol. 80, no. 4, pp. 1539-1541, 2014.

[72] B. Nusslein, K.-J. Chin, W. Eckert, and R. Conrad, "Evidence for anaerobic syntrophic acetate oxidation during methane production in the profundal sediment of subtropical Lake Kinneret (Israel)," Environmental Microbiology, vol. 3, no. 7, pp. 460-470, 2001.

[73] E. A. Gies, K. M. Konwar, J. T. Beatty, and S. J. Hallam, "Illuminating microbial dark matter in meromictic Sakinaw Lake," Applied and Environmental Microbiology, vol. 80, no. 21, pp. 6807-6818, 2014.

[74] M. Westerholm, B. Müller, A. Singh, O. Karlsson Lindsjö, and A. Schnürer, "Detection of novel syntrophic acetate-oxidizing bacteria from biogas processes by continuous acetate enrichment approaches," Microbial Biotechnology, vol. 11, no. 4, pp. 680-693, 2018.

[75] M. Westerholm, J. Moestedt, and A. Schnürer, "Biogas production through syntrophic acetate oxidation and deliberate operating strategies for improved digester performance," Applied Energy, vol. 179, pp. 124-135, 2016.

[76] B. E. Jackson, V. K. Bhupathiraju, R. S. Tanner, C. R. Woese, and M. J. McInerney, "Syntrophus aciditrophicus sp. nov., a new anaerobic bacterium that degrades fatty acids and benzoate in syntrophic association with hydrogen-using microorganisms," Archives of Microbiology, vol. 171, no. 2, pp. 107-114, 1999.

[77] H. Dahle and N.-K. Birkeland, "Thermovirga lienii gen. nov., sp. nov., a novel moderately thermophilic, anaerobic, aminoacid-degrading bacterium isolated from a North Sea oil well," International Journal of Systematic and Evolutionary Microbiology, vol. 56, no. 7, pp. 1539-1545, 2006.

[78] Y. L. Qiu, S. Hanada, Y. Kamagata, R. B. Guo, and Y. Sekiguchi, "Lactivibrio alcoholicus gen. nov., sp. nov., an anaerobic, mesophilic, lactate-, alcohol-, carbohydrate- and amino-acid-degrading bacterium in the phylum Synergistetes," International Journal of Systematic and Evolutionary Microbiology, vol. 64, Part 6, pp. 2137-2145, 2014.

[79] T. Honda, T. Fujita, and A. Tonouchi, “Aminivibrio pyruvatiphilus gen. nov., sp. nov., an anaerobic, amino-acid-degrading bacterium from soil of a Japanese rice field," International 
Journal of Systematic and Evolutionary Microbiology, vol. 63, Part 10, pp. 3679-3686, 2013.

[80] F. Mosbæk, H. Kjeldal, D. G. Mulat et al., "Identification of syntrophic acetate-oxidizing bacteria in anaerobic digesters by combined protein-based stable isotope probing and metagenomics," The ISME Journal, vol. 10, no. 10, pp. 2405-2418, 2016.

[81] T. Ito, K. Yoshiguchi, H. D. Ariesyady, and S. Okabe, "Identification of a novel acetate-utilizing bacterium belonging to Synergistes group 4 in anaerobic digester sludge," The ISME Journal, vol. 5, no. 12, pp. 1844-1856, 2011.

[82] A. E. Rotaru, P. M. Shrestha, F. Liu et al., "A new model for electron flow during anaerobic digestion: direct interspecies electron transfer to Methanosaeta for the reduction of carbon dioxide to methane," Energy \& Environmental Science, vol. 7, no. 1, pp. 408-415, 2014.

[83] N. D. Gray, A. Sherry, R. J. Grant et al., "The quantitative significance of Syntrophaceae and syntrophic partnerships in methanogenic degradation of crude oil alkanes," Environmental Microbiology, vol. 13, no. 11, pp. 2957-2975, 2011.

[84] B. Schink, "Energetics of syntrophic cooperation in methanogenic degradation," Microbiology and Molecular Biology Reviews, vol. 61, no. 2, pp. 262-280, 1997.

[85] Y. Sekiguchi, Y. Kamagata, K. Nakamura, A. Ohashi, and H. Harada, "Fluorescence in situ hybridization using $16 \mathrm{~S}$ rRNA-targeted oligonucleotides reveals localization of methanogens and selected uncultured bacteria in mesophilic and thermophilic sludge granules," Applied and Environmental Microbiology, vol. 65, no. 3, pp. 1280-1288, 1999. 


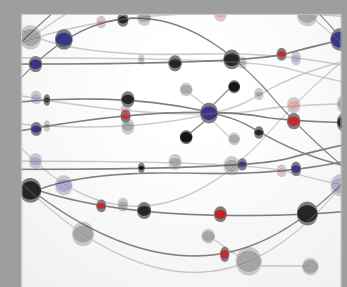

The Scientific World Journal
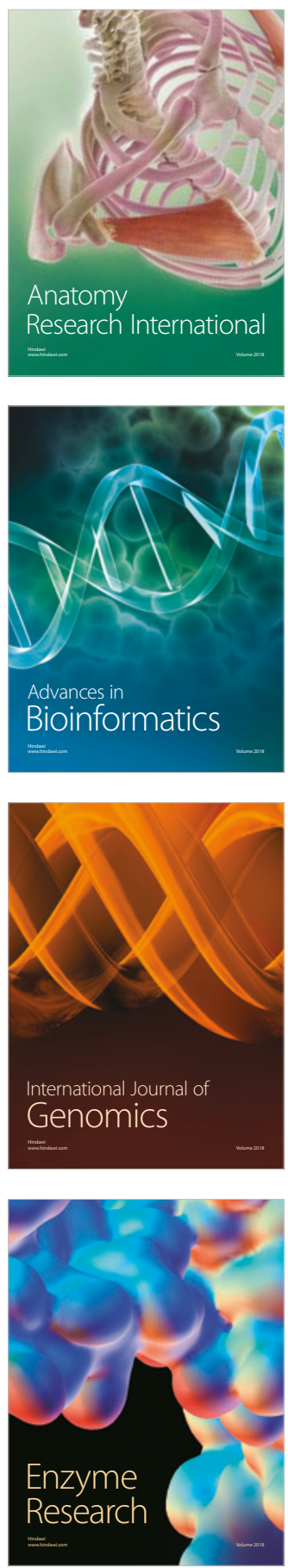
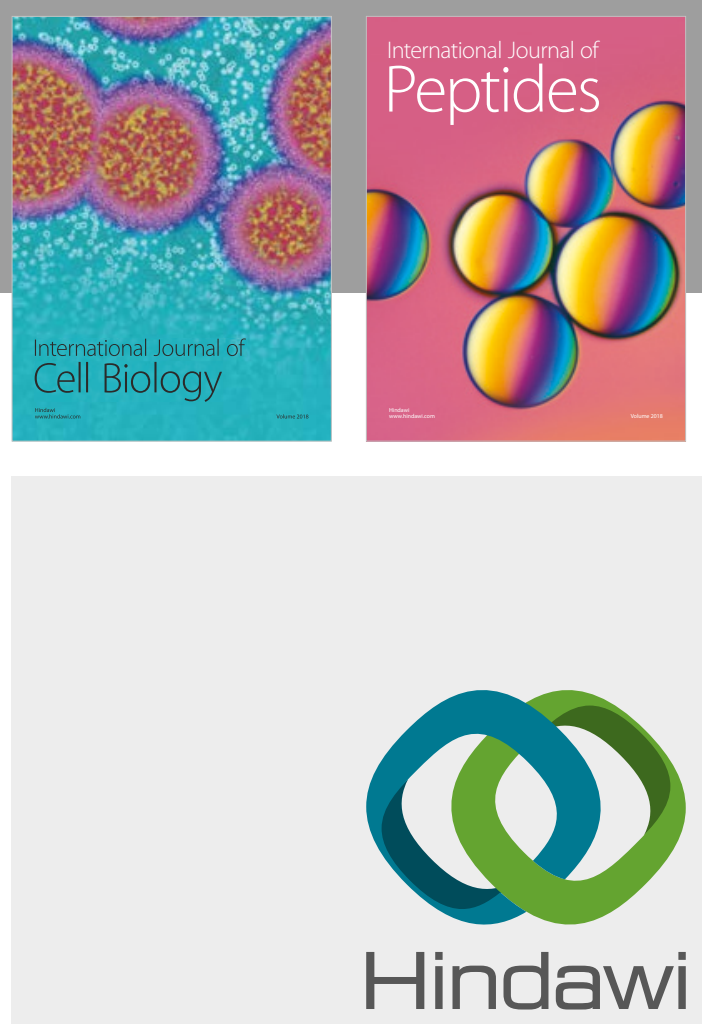

Submit your manuscripts at

www.hindawi.com
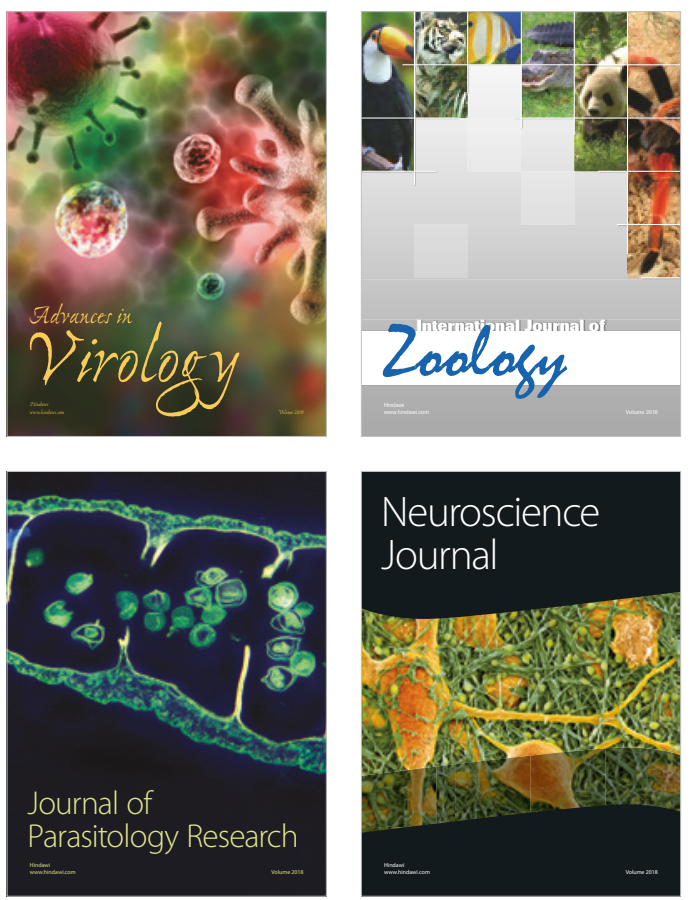
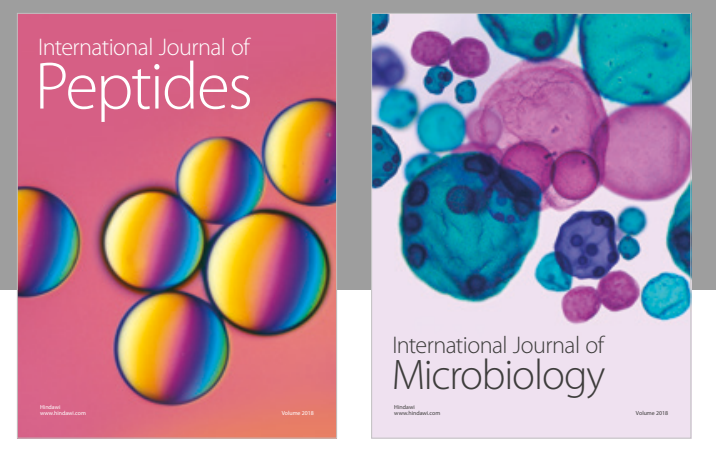

nternational Journal of Microbiology
Journal of
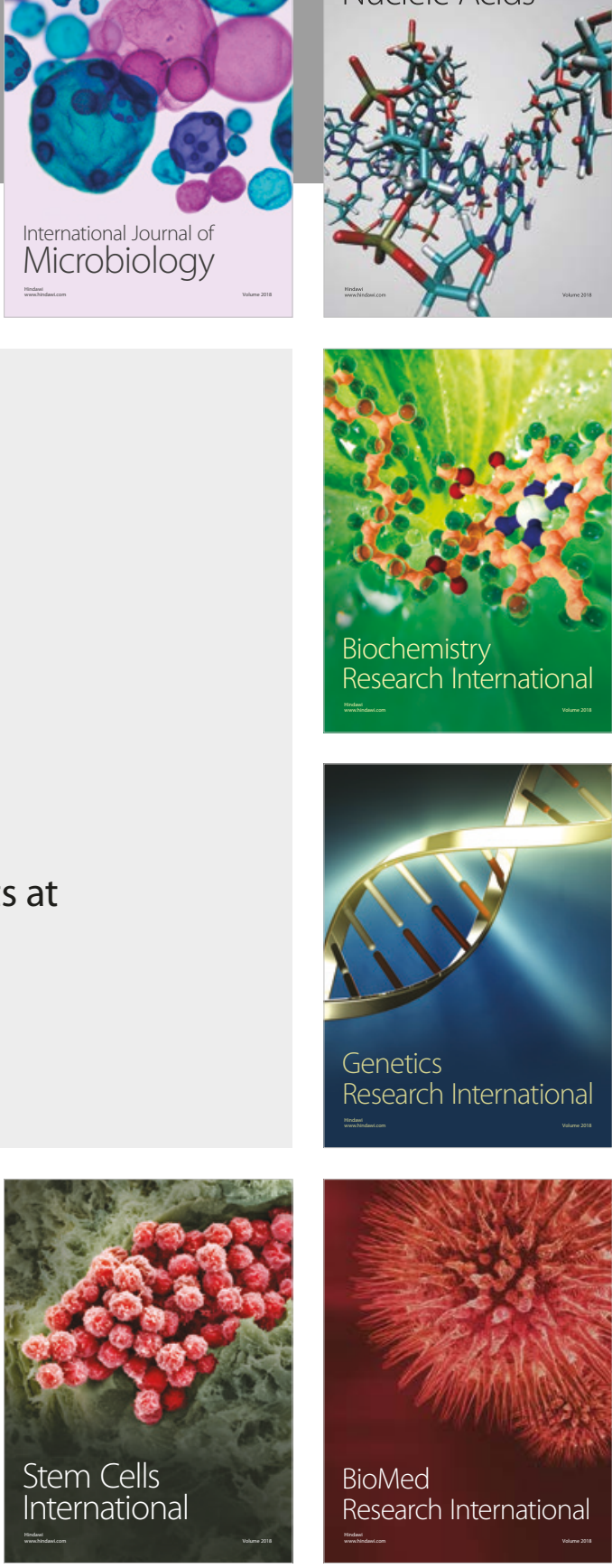
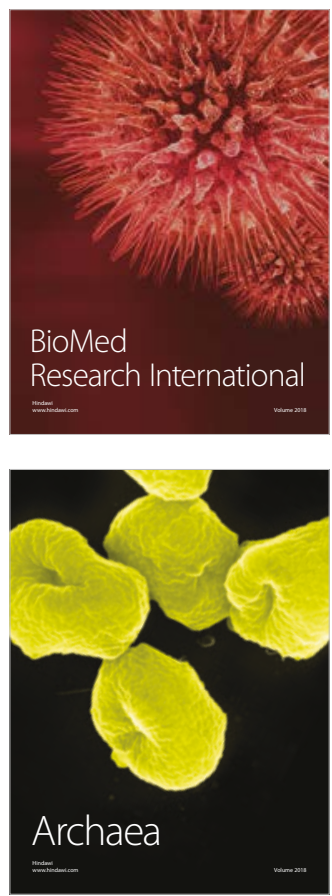